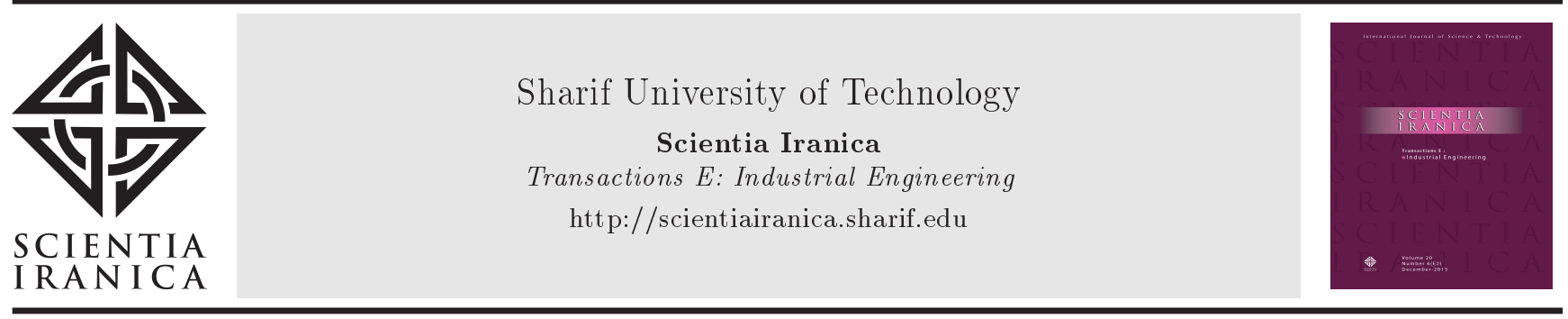

\title{
A mathematical model for the joint planning of maintenance and safety stock in deteriorating imperfect manufacturing systems
}

\author{
S.M. Hadian ${ }^{a}$, H. Farughi ${ }^{a, *}$, and H. Rasay ${ }^{b}$ \\ a. Department of Industrial Engineering, Engineering College, University of Kurdistan, Pasdaran, Sanandaj, Iran. \\ b. Department of Industrial Engineering, Kermanshah University of Technology, Imam Khomeini, Kermanshah, Iran. \\ Received 3 May 2020; received in revised form 6 September 2020; accepted 15 February 2021
}

\author{
KEYWORDS \\ Deteriorating \\ production system; \\ Maintenance \\ planning; \\ Preventive \\ maintenance; \\ Inventory control; \\ Safety stock.
}

\begin{abstract}
The current study proposes a mathematical model for joint planning of maintenance policies and inventory control in a deteriorating production system. In this regard, a safety stock is maintained to meet the demands during the conduction of maintenance actions and avoid shortages. The optimal planning of maintenance and inventory considerably improves the productivity of the manufacturing system. In a deteriorating production system, the process has two operational states, i.e., in-control and out-of-control states, as well as a non-operational state or failure mode. The time for the transition from one state to another follows a general continuous distribution. In addition, the time duration of maintenance actions is considered a random variable. The main objective of this study is to optimize the safety stock level and time to conduct maintenance actions in order to minimize the expected total cost per time unit. To verify the efficiency of the proposed model, some numerical examples are solved using a genetic algorithm and the solutions are verified. Finally, sensitivity analyses are carried out on the critical parameters.
\end{abstract}

(C) 2023 Sharif University of Technology. All rights reserved.

\section{Introduction}

In [1], maintenance planning, production/inventory control, and quality control were regarded the main operational policies affecting the performance of manufacturing systems. Joint consideration of these factors can lead to ideal and optimal planning of production processes and improvement of productivity in manufac-

*. Corresponding author. Tel.: 0988733664600

E-mail addresses: M.hadian@eng.uok.ac.ir (S.M. Hadian);

h.farughi@uok.ac.ir (H. Farughi); Hasan.Rasay@gmail.com (H. Rasay)

doi: $10.24200 /$ sci.2021.55904.4459 turing systems. As stated in [2], the role, conditions, and availability of machines were important factors in production and inventory control. Considering the relationship among machinery maintenance, inventory level, and product quality, some authors have focused on the joint planning of maintenance, inventory, and quality control as the important actions to take on the management of manufacturing systems [3]. For years, these actions have been taken separately; however, some integrated models have been recently developed for their joint planning. Of note, there are interactions and interrelationships among maintenance planning, production/inventory control, and quality control that form the basis of integrated models [4].

Maintenance planning can reduce the downtime of 
the machines and increase their availability. There are different methods to restore and maintain production processes in an optimal condition. Effective maintenance reduces the overall cost of the company because production capacity is available when needed. Maintenance planning involves identification of the necessary parts and tools for the job. While taking maintenance actions on the machines, the production process is interrupted and production is stopped. Therefore, a safety stock is required to meet the demand and avoid possible stock-out during the maintenance operation.

Classical Economic Manufacturing Quantity (EMQ) models generally ignore deterioration in production processes, assuming that machines do not break down [5]. In real-world situations, however, the production process in most manufacturing systems is imperfect. To be specific, production of defective items results from the deterioration of the processes and failure of the machines [1]. Deteriorating production processes have generally two operational states, called in-control and out-of-control states, and a nonoperational state called the failure mode. While the products are produced with high quality in the incontrol state, quality, the quality of the produced items in the out-of-control state may be reduced, hence production of defective items. This happens mainly because the machines are held responsible for the production, but an assignable cause pushes the process to deterioration. In the failure state, the machine that breaks down cannot produce items, thus interrupting the production process. In such systems, the process is initially under control; however, as time goes by, the machines deteriorate and the process state is shifted to an out-of-control state.

Different policies can be implemented to control the quality of products and number of detected defective items. Sometimes, defective items cannot be detected unless the consumers use them. In the current study, a warranty policy is taken into consideration to detect these products. In other words, all products are sold with a warranty period. If an item is found to be defective within this period, it will be repaired.

The impact of deterioration on the production planning in manufacturing systems has been examined in different studies. For instance, Porteus [6] and Rosenblatt and Lee [7] were the first researchers to have studied the impact of deterioration on the manufacturing systems. They considered a production process with two operational states where the process state transition followed an exponential distribution. Groenevelt et al. [8] presented an EMQ model considering the deterioration. They also took into account an exponential distribution for the process state transition and ignored the repair time. Goyal and Barron [9] studied an imperfect production system and presented an EMQ model with the objective of minimizing the total cost. Chakraborty et al. [10] developed some integrated models for process deterioration, inspection, and maintenance.

The interrelations of production/inventory control, maintenance planning, and quality control have been studied and analyzed based on different policies specific to production control and quality control. Sana [11] presented a model for an imperfect manufacturing system. He evaluated the impact of deterioration on a process with the possibility of a shift from an in-control state to an out-of-control state. He also assumed that defective products were likely to be produced in the out-of-control state and that they could be detected by inspection and restored in high quality by reworking. In this study, it was also assumed that the probability of the production of defective items in the out-of-control state depended on the production rate and runtime. The model primarily aimed to determine the optimal production lot size to minimize the total cost. Chakraborty and Giri [5] developed an EMQ model for a deteriorating process. In their study, the process state could be shifted from an incontrol state to an out-of-control state or from an outof-control state to a failure mode. They considered a general distribution for the time duration of the maintenance actions. Their proposed model aimed to jointly plan maintenance and determine an optimal safety stock level to minimize the total cost. They also proposed a computational algorithm to optimize the model. Sarkar [12] established an inventory model for imperfect production processes considering the effect of inflation. The process could shift from an in-control state to an out-of-control state. They assumed that the defective products were produced in the out-of-control state; hence, they could be detected by inspection and reworked. The main purpose of their model was to determine the optimal production lot size to minimize the total cost.

Horenbeek et al. [13] reviewed the models for integrated optimization of maintenance and inventory. Sarkara et al. [14] developed an Economic Production Quantity (EPQ) model for imperfect production systems. Assuming that the defective products could be reworked, they developed three different inventory models for three different distribution functions for the time of the state transition in a production process. Sett et al. [15] studied the joint planning of maintenance, quality, and inventory control. According to their assumptions, a safety stock should be maintained to avoid shortage. The process was likely to transit from an in-control state to an out-of-control state at any random time, and the shift time followed a general distribution. Defective items could be produced in both in-control and out-of-control states. They considered a free repair warranty for non-inspected sold items. Salmasnia et al. [2] studied the joint 
planning of EMQ, quality, and maintenance. They considered the deterioration in a production process with two operational states and conducted Preventive Maintenance (PM) and Corrective Maintenance (CM) actions for maintenance. The time duration of the maintenance actions was considered constant. In this study, an X-bar control chart was used for process monitoring. In addition, Particle Swarm Optimization (PSO) algorithm was used for optimization. Lopes [1] developed a mathematical model to simultaneously plan the quality control, maintenance, and production for an imperfect manufacturing system. He referred to the PM as the maintenance policy and the PM time duration as a random variable. In this study, it was assumed that a safety stock should be maintained to avoid shortage during the performance of the PM action. The produced items were inspected and all products were sold with a free minimal repair warranty. Duffuaa et al. [16] presented a model to simultaneously plan production, maintenance, and quality. In this regard, they first optimized a PM schedule. Then, they did production scheduling and inventory control. They identified three states for the process where the time of transition among the states followed an exponential distribution. An X-bar control chart was applied to monitor the process and control the quality. The duration of the maintenance actions was considered constant.

Nourelfath et al. [17] presented a model to plan production, maintenance, and quality in an imperfect manufacturing system considering a multi-period multi-product system. They assumed that the process contained two operational states and the process shift would follow a general distribution. The products were inspected during the production cycle to control their quality. The model primarily aimed to determine the optimal safety sock level and production run length to minimize the total cost. Fakher et al. [18] presented a model to plan maintenance, quality, and production in a capacitated manufacturing system and performed some computational experiments to analyze their interrelationship. The process contained three states, and the transition time among the states followed the Weibull distribution. The produced items were inspected to control their quality. The duration of the maintenance actions was constant. The purpose of the model was to determine the production lot size and maximize the profit. Cheng et al. [19] presented a mathematical model to plan production, quality inspection, and maintenance with deterioration taken into account. The process had three states, and the transition time among the states followed a gamma stochastic trend. The duration of the maintenance actions was considered a random variable. A safety stock was maintained to avoid any possible stockout against uncertainties. In this study, a 100\% inspection was done as part of the quality control policy and the production lot size was determined based on the maintenance planning and quality control policy. Finally, a simulation technique was employed for optimization.

Shafiee-Gol et al. [20] developed an EPQ model for imperfect production processes and studied the pricing and production decisions in multi-product single-machine manufacturing systems. Their study included the inspection of all the produced items and reworking of the defective ones. Hafidi et al. [21] presented an integrated model of production, maintenance, and quality control in deterioration manufacturing systems. They developed a multi-item capacitated lot-sizing problem and considered subcontracting strategies in the integrated model. They used a genetic algorithm for optimization. Gomez et al. [22] proposed an integrated model of production, maintenance, and quality control for a continuous production system with quality deterioration. They presented a dynamic sampling strategy for inspection and quality control and analyzed the interactions among the sampling, production, and maintenance strategies. The purpose of the research was to determine an optimal production policy, schedule PM, and implement a quality control policy to minimize the expected total cost of the system. Salmasnia et al. [23] presented an integrated model of production cycle length, maintenance policy, and quality control. They also took into consideration the time value of money and stochastic shift size. The main objective of the model was to determine the production cycle length, maintenance policy, and economic-statistical design of a control chart. Wang et al. [24] developed an integrated model of production, maintenance, and quality control for a serial production system with stochastic deterioration. To produce each production lot, an inspection was conducted on the process. In order to determine the situation of the machines, a predictive maintenance policy was practiced based on the predictive failure probability of each machine. Their proposed model aimed to minimize the total cost of the system. A simulation-based approach was used for optimization. For comparison purposes, Table 1 summarizes the main features of the most important studies mentioned above.

Chakraborty and Giri [5] devised a mathematical model to jointly plan the inventory control and maintenance. They adopted a warranty period policy to detect the defective sold products.

In our study, a mathematical model is presented for the joint planning of maintenance and inventory. For this purpose, the impact of deterioration on the process is taken into account. The process has three states including an in-control state, out-ofcontrol state, and failure mode. The transitions of the process among these states are based on general 
Table 1. Comparison of different studies on integrated models.

\begin{tabular}{|c|c|c|c|c|c|c|c|c|c|}
\hline \multirow[b]{2}{*}{ Refs. } & \multirow[b]{2}{*}{$\begin{array}{c}\text { Number } \\
\text { of process } \\
\text { states }\end{array}$} & \multicolumn{3}{|c|}{ Process state transition } & \multirow[b]{2}{*}{$\begin{array}{c}\text { Failure } \\
\text { mechanism }\end{array}$} & \multirow[b]{2}{*}{$\begin{array}{l}\text { Quality control } \\
\text { policy }\end{array}$} & \multirow[b]{2}{*}{$\begin{array}{l}\text { Repair } \\
\text { time }\end{array}$} & \multirow[b]{2}{*}{$\begin{array}{c}\text { Production / } \\
\text { inventory } \\
\text { control } \\
\text { policy }\end{array}$} & \multirow[b]{2}{*}{$\begin{array}{l}\text { Inventory } \\
\text { shortage } \\
\text { consideration }\end{array}$} \\
\hline & & $\begin{array}{c}\text { In- } \\
\text { control } \\
\text { to out } \\
\text {-of- } \\
\text { control }\end{array}$ & $\begin{array}{c}\text { Out- } \\
\text { of- } \\
\text { control tc } \\
\text { failure }\end{array}$ & $\begin{array}{c}\text { In- } \\
\text { control } \\
\text { to } \\
\text { failure }\end{array}$ & & & & & \\
\hline$[1]$ & 2 & $\sqrt{ }$ & & & $\begin{array}{l}\text { Random variable with } \\
\text { general distribution }\end{array}$ & $\begin{array}{l}\text { Product inspection } \\
\text { and warranty period }\end{array}$ & $\begin{array}{l}\text { Random } \\
\text { variable }\end{array}$ & $\begin{array}{l}\text { Determination of } \\
\text { safety stock }\end{array}$ & $\sqrt{ }$ \\
\hline$[2]$ & 2 & $\sqrt{ }$ & & & $\begin{array}{l}\text { Random variable with } \\
\text { Weibull distribution }\end{array}$ & $\mathrm{X}$-bar control chart & Constant & $\mathrm{EPQ}$ & \\
\hline$[5]$ & 3 & $\sqrt{ }$ & $\sqrt{ }$ & & $\begin{array}{l}\text { Random variable with } \\
\text { general distribution }\end{array}$ & Warranty period & $\begin{array}{l}\text { Random } \\
\text { variable }\end{array}$ & $\begin{array}{l}\text { Determination of } \\
\text { safety stock } \\
\text { and production } \\
\text { run length }\end{array}$ & $\sqrt{ }$ \\
\hline$[11]$ & 2 & $\sqrt{ }$ & & & $\begin{array}{l}\text { Random variable with } \\
\text { exponential distribution }\end{array}$ & Product inspection & - & $\begin{array}{l}\text { Determination of } \\
\text { production lot } \\
\text { siz }\end{array}$ & \\
\hline$[12]$ & 2 & $\sqrt{ }$ & & & $\begin{array}{l}\text { Random variable with } \\
\text { general distribution }\end{array}$ & Product inspection & - & $\begin{array}{l}\text { Determination of } \\
\text { production lot } \\
\text { size }\end{array}$ & \\
\hline$[15]$ & 2 & $\sqrt{ }$ & & & $\begin{array}{l}\text { Random variable with } \\
\text { general distribution }\end{array}$ & $\begin{array}{l}\text { Product inspection and } \\
\text { warranty period }\end{array}$ & $\begin{array}{l}\text { Random } \\
\text { variable }\end{array}$ & $\begin{array}{l}\text { Determination of } \\
\text { buffer inventory }\end{array}$ & $\sqrt{ }$ \\
\hline$[16]$ & 3 & $\sqrt{ }$ & $\sqrt{ }$ & & $\begin{array}{l}\text { Random variable with } \\
\text { exponential distribution }\end{array}$ & $\mathrm{X}$-bar control chart & Constant & Production scheduling & \\
\hline$[17]$ & 2 & $\sqrt{ }$ & & & $\begin{array}{l}\text { Random variable with } \\
\text { general distribution }\end{array}$ & Product inspection & Constant & $\begin{array}{l}\text { Determination of } \\
\text { safety stock and } \\
\text { production run length }\end{array}$ & $\sqrt{ }$ \\
\hline$[18]$ & 3 & $\sqrt{ }$ & $\sqrt{ }$ & & $\begin{array}{l}\text { Random variable with } \\
\text { Weibull distribution }\end{array}$ & Product inspection & Constant & $\begin{array}{l}\text { Determination of } \\
\text { production lot } \\
\text { size }\end{array}$ & $\sqrt{ }$ \\
\hline$[19]$ & 3 & $\sqrt{ }$ & $\sqrt{ }$ & & $\begin{array}{l}\text { Random variable with } \\
\text { gamma distribution }\end{array}$ & $100 \%$ inspection & $\begin{array}{l}\text { Random } \\
\text { variable }\end{array}$ & $\begin{array}{l}\text { Determination of } \\
\text { production lot } \\
\text { size }\end{array}$ & $\sqrt{ }$ \\
\hline$[20]$ & - & & & & & $100 \%$ inspection & - & $\begin{array}{l}\text { Determination of } \\
\text { production lot } \\
\text { size }\end{array}$ & \\
\hline$[21]$ & 2 & $\sqrt{ }$ & & & $\begin{array}{l}\text { Random variable with } \\
\text { general distribution }\end{array}$ & Periodic inspection & Constant & $\begin{array}{l}\text { Determination of } \\
\text { production lot } \\
\text { size }\end{array}$ & $\sqrt{ }$ \\
\hline$[22]$ & - & & & & Number of repairs & Sampling plan & $\begin{array}{l}\text { Random } \\
\text { variable }\end{array}$ & $\begin{array}{l}\text { Determination of } \\
\text { production lot } \\
\text { size }\end{array}$ & $\sqrt{ }$ \\
\hline$[23]$ & 2 & $\sqrt{ }$ & & & $\begin{array}{l}\text { Random variable with } \\
\text { Weibull distribution }\end{array}$ & $\mathrm{X}$-bar control chart & Constant & $\begin{array}{l}\text { Determination of } \\
\text { production run } \\
\text { length and } \\
\text { inventory level }\end{array}$ & \\
\hline$[24]$ & 2 & $\sqrt{ }$ & & & $\begin{array}{l}\text { Random variable with } \\
\text { gamma distribution }\end{array}$ & Periodic inspection & Constant & $\begin{array}{l}\text { Determination of } \\
\text { production run } \\
\text { length and } \\
\text { inventory level }\end{array}$ & $\sqrt{ }$ \\
\hline $\begin{array}{l}\text { This } \\
\text { paper }\end{array}$ & 3 & $\sqrt{ }$ & $\sqrt{ }$ & $\sqrt{ }$ & $\begin{array}{l}\text { Random variable with } \\
\text { general distribution }\end{array}$ & Warranty period & $\begin{array}{l}\text { Random } \\
\text { variable }\end{array}$ & $\begin{array}{l}\text { Determination of } \\
\text { safety stock } \\
\text { and production } \\
\text { run length }\end{array}$ & $\sqrt{ }$ \\
\hline
\end{tabular}


continuous random variables. The repair duration is also considered a random variable. The objective of the proposed model was to determine an optimal safety stock level and a time to conduct maintenance actions and consequently minimize the expected total cost of the process.

The structure of this study is as follows. The statement of the problem is presented in Section 2. Different scenarios during a production cycle are explained in Section 3. The proposed integrated model is developed in Section 4. Numerical studies and sensitivity analysis are elaborated in Section 5. The concluding remarks of the this research are given in Section 6 .

\section{Problem description}

\section{Notations}

The following notations were considered in developing the integrated model:

$X_{1}$

The time of transition from the in-control state to the out-of-control state (continuous random variable)

$f_{1}\left(x_{1}\right) \quad$ Probability density function (p.d.f) of $X_{1}$

$F_{1}\left(x_{1}\right) \quad$ Cumulative distribution function (c.d.f) of $X_{1}$

$\bar{F}_{1}\left(x_{1}\right) \quad$ The survivor function, $1-F_{1}$

$X_{2} \quad$ The time of transition from the out-of-control state to the failure mode (continuous random variable)

$f_{2}\left(x_{2}\right) \quad$ p.d.f of $X_{2}$

$F_{2}\left(x_{2}\right) \quad$ c.d.f of $X_{2}$

$\bar{F}_{2}\left(x_{2}\right) \quad$ The survivor function, $1-F_{2}$

$X_{3} \quad$ The time of transition from the in-control state to the failure mode (continuous random variable)

$$
\begin{aligned}
& f_{3}\left(x_{3}\right) \\
& F_{3}\left(x_{3}\right) \\
& \bar{F}_{3}\left(x_{3}\right) \\
& Z_{1}
\end{aligned}
$$$$
\text { p.d.f of } X_{3}
$$

c.d.f of $X_{3}$

$$
\text { The survivor function, } 1-F_{3}
$$

$g_{1}\left(z_{1}\right)$ Time duration required for conducting $\mathrm{CM}$ action (random variable)

$G_{1}\left(z_{1}\right)$

$Z_{2}$

p.d.f of $Z_{1}$

c.d.f of $Z_{1}$

$g_{2}\left(z_{2}\right)$

Time duration required for conducting PM action (random variable)

$G_{2}\left(z_{2}\right)$

p.d.f of $Z_{2}$
$T$

$q_{1}$

$$
\begin{array}{ll}
q_{2}\left(q_{2} \geq q_{1}\right) & \begin{array}{l}
\text { Maximum production rate of the } \\
\text { machine }
\end{array} \\
& \begin{array}{l}
\text { The probability of producing defective } \\
\text { products when the process is in the } \\
\text { out-of-control state }
\end{array} \\
C_{h} & \text { The unit cost of inventory holding } \\
C_{s} & \text { The unit cost of shortage } \\
C_{C M} & \text { The unit cost of CM action } \\
C_{P M} & \text { The unit cost of PM action } \\
\left(C_{P M}<C_{C M}\right) & \text { The average setup cost } \\
C_{\text {setup }} & \text { A known constant free repair warranty } \\
w & \text { period } \\
& \text { The unit cost of minimal repair during } \\
C_{w} & \text { the period } w \\
N & \text { The number of defective products in a } \\
& \text { cycle } \\
h(k) & \text { Hazard rate function for a defective } \\
& \text { item for } k \geq 0
\end{array}
$$

Consider a process where a type of product is produced at a given constant rate equal to the demand rate. The process has two operational states, including an in-control state and an out-of-control state, and a non-operational state, i.e., a failure mode. In this study, the in-control state, out-of-control state, and failure mode are assigned 0,1 , and $F$, respectively. Each production cycle starts in state 0 to satisfy the demand $q_{1}$ per a time unit. The process state may transit from state 0 to state 1 at any random time during a production run. In addition, the process state may transit from state 0 to the failure mode without transition to state 1 or from state 1 to the failure mode. Figure 1 illustrates the transitions among the states of the process.

The items produced in state 1 may be defective with a certain probability, while those produced in state 0 are all conforming.

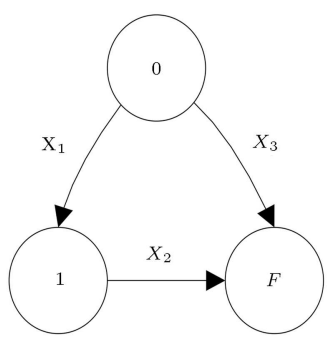

Figure 1. Transition among the process states. 
If a machine breaks down during the production run, a CM action is conducted on the process. Otherwise, PM is conducted on the process after $T$ unit of time regardless of the process state. The time durations of the CM and PM actions are considered random variables. The production process is interrupted during the maintenance actions, and the demand is satisfied from the safety stock $S$ to avoid any shortage. Therefore, the safety stock level reduces at the demand rate $q_{1}$. The PM and CM actions are perfect, indicating that after the maintenance actions, the machine returns to an as-good-as-new condition and then, the production continues at the maximum rate $q_{2}$ until the stock level reaches $S$ again. Next, the production rate is set at the normal level $q_{1}\left(q_{1}<q_{2}\right)$. The production cycle in this case is the time duration from the start of the process until the safety stock level reaches $S$ again.

If the maintenance action is completed before $\frac{S}{q_{1}}$, no shortage will occur. Followed by the maintenance action, the process continues at the maximum rate $q_{2}$ until the stock level becomes $S$ again. If the maintenance action is completed after $\frac{S}{q_{1}}$, shortage is likely to occur. When this shortage occurs after the completion of the maintenance action, the machine starts to produce the products and the safety stock level becomes $S$ again within the time duration of $\frac{S}{q_{2}-q_{1}}$. The demands that are not met during the maintenance actions are lost. It is assumed that the defective products in this study cannot be detected unless the consumers use them. Therefore, to detect the defective items, all products are sold with a free minimal repair warranty within the warranty period $w$. Under this policy, if a sold product fails within the period $w$, it is given a minimal repair at the cost $C_{w}$ to return it to the same condition as it used to be in. The procedure described for modeling can be put into practice in the real-world situations such as automobile industry. Car manufacturers and dealers use warranties to win and retain customers. Some non-conforming items in cars are operational, but they cannot be detected unless the consumers use them. Changing a flat tire on a car, rectifying an ignition or wiring system, changing a broken fan below an engine, or any repair of the engine that does not change the overall performance of the car are some examples of minimal repair.

The main objective of the proposed model is to plan the maintenance and the inventory control simultaneously to optimize the safety stock level $(S)$ and time of performing the PM action $(T)$ to minimize the expected total cost of the process per unit of time.

\section{Possible scenarios during a production cycle}

Four scenarios may occur for the process completion during each production cycle:

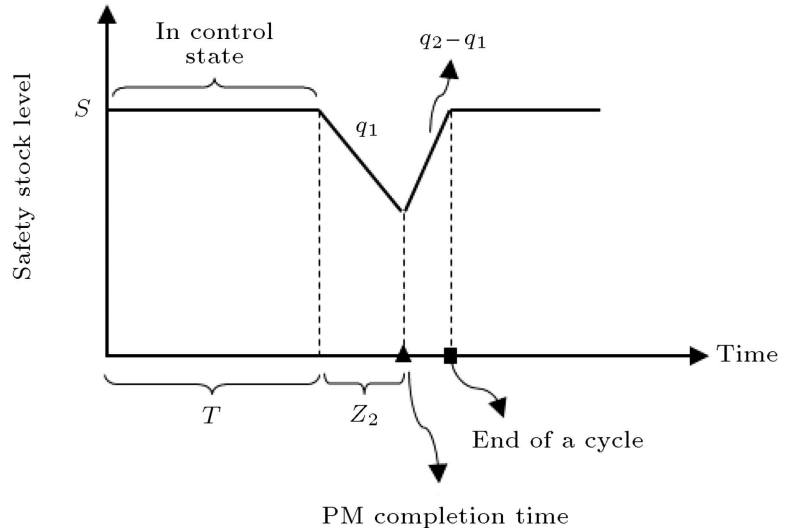

(a)

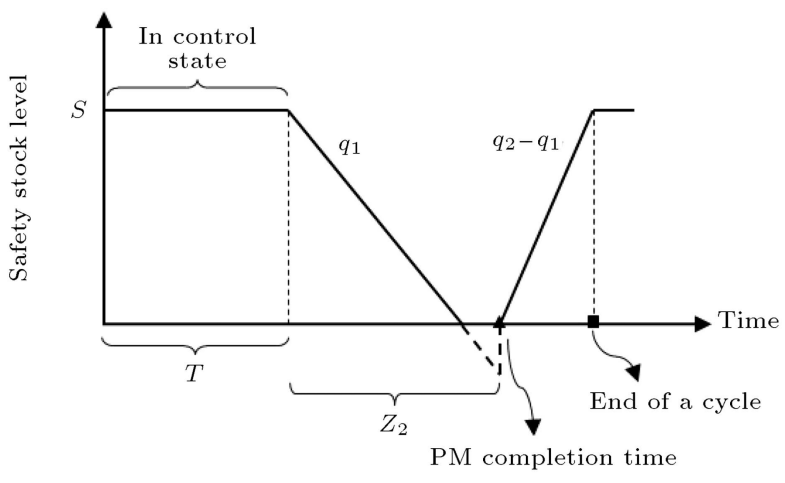

(b)

Figure 2. Evolution of the process corresponding to Scenario 1: (a) Without shortage and (b) with shortage.

Scenario 1: In this scenario, the process remains in State 0 up to the time point $T$. In other words, the process state transits neither to state 1 nor to the failure state. Therefore, at time $T$, the process is stopped and PM is conducted. Figure 2 illustrates the evolution of the process under this scenario. Figure 2(a) corresponds to the case where the duration of the PM action is shorter than $\frac{S}{q_{1}}$, hence no shortage occurrence. On the contrary, as observed in Figure 2(b), the duration of the PM action is longer than $\frac{S}{q_{1}}$, hence shortage occurrence. Followed by completion of the PM action, the production starts at the rate $q_{2}\left(q_{2}>q_{1}\right)$ until the safety stock reaches $S$ again. Then, the production continues at a normal rate, $q_{1}$. This scenario occurs with the probability in Eq. (1):

$$
P\left(S_{1}\right)=\bar{F}_{1}(T) \bar{F}_{3}(T) .
$$

Scenario 2: The production process initially operates in state 0 and transits to state 1 after a random time interval as $x_{1}$ from the start of the cycle. The process operates under state 1 until $T$, when the PM action is implemented. Figure 3 illustrates the process under this scenario. According to Figure 3(a), the duration of the PM action is shorter than $\frac{S}{q_{1}}$, hence no shortage 


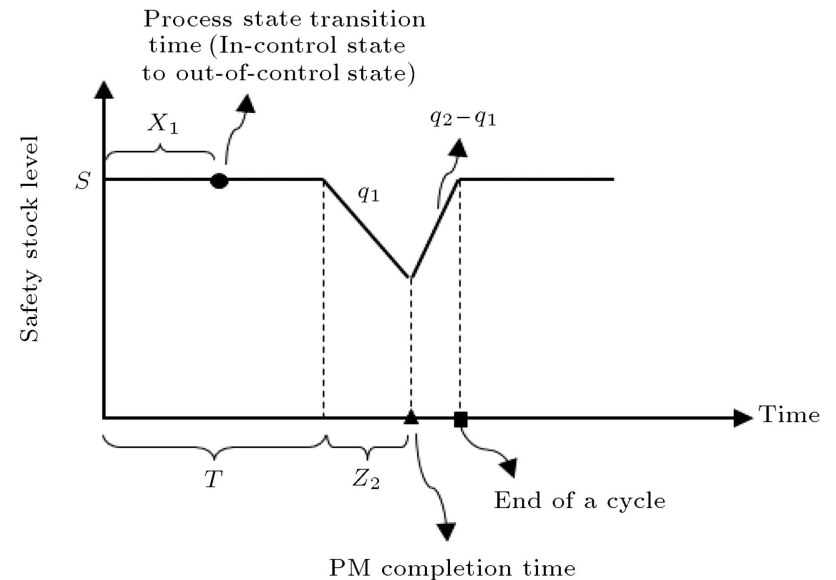

(a)

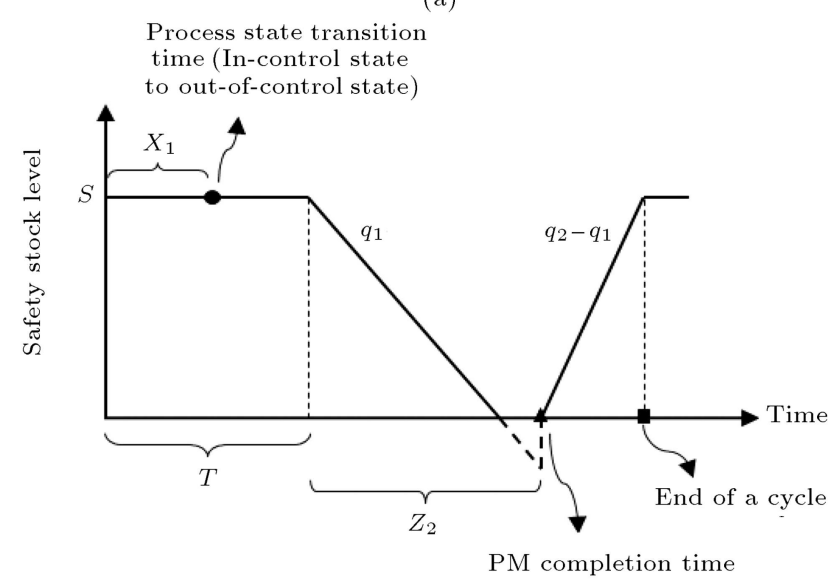

(b)

Figure 3. Evolution of the process corresponding to Scenario 2: (a) Without shortage and (b) with shortage.

occurrence. On the contrary, Figure 3(b) corresponds to the case where a shortage occurs as the duration of the PM action is longer than $\frac{S}{q_{1}}$. This scenario occurs at a probability measured in Eq. (2):

$$
P\left(S_{2}\right)=\int_{0}^{T} f_{1}(x) \bar{F}_{3}(x) \frac{\bar{F}_{2}(T)}{\bar{F}_{2}(x)} d x .
$$

Scenario 3: With the passage of a random time duration $x_{3}$ from the beginning of the cycle, the process directly shifts from state 0 to the failure mode without transition to state 1 . Once the process state transits to the failure mode, CM is conducted. Figure 4 illustrates the evolution of the process under this scenario. Figure 4(a) indicates that the duration of the CM action is shorter than $\frac{S}{q_{1}}$, hence no shortage occurrence. Figure 4(b), however, indicates that a shortage occurs when the duration of the CM action is longer than $\frac{S}{q_{1}}$. This scenario occurs at a probability measured in Eq. (3):

$$
P\left(S_{3}\right)=\int_{0}^{T} f_{3}(x) \bar{F}_{1}(x) d x .
$$

Scenario 4: After a random time duration $x_{1}$ from

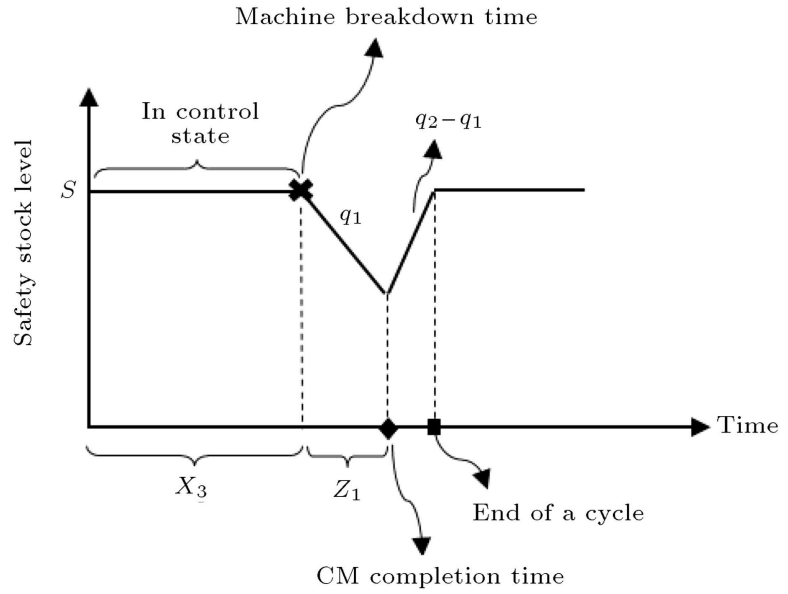

(a)

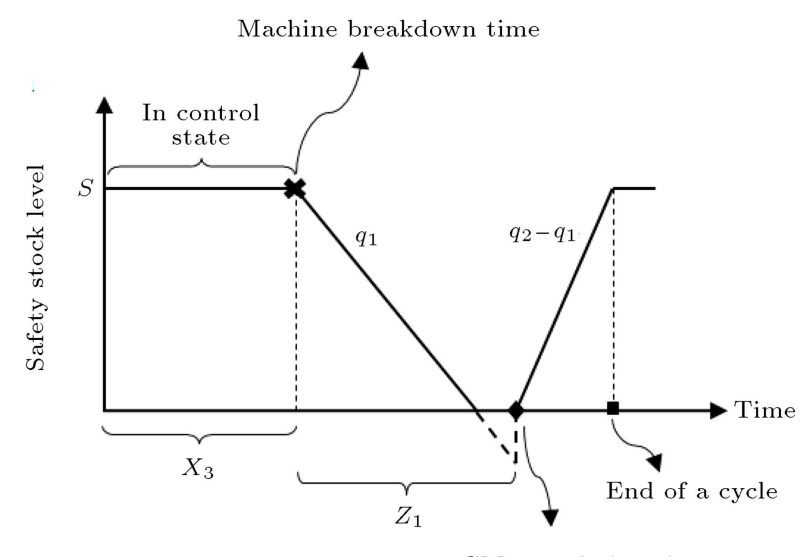

CM completion time

(b)

Figure 4. Evolution of the process corresponding to Scenario 3: (a) Without shortage and (b) with shortage.

the beginning of the cycle, the process shifts to state 1 . Then, the process at random time $x_{2}\left(x_{1}<x_{2}<T\right)$ shifts to the failure state. Once the failure state starts, $\mathrm{CM}$ is conducted. After the completion of the CM action, the production starts at the maximum rate $\left(q_{2}\right)$. Production at rate $q_{2}$ continues until the safety stock becomes $S$ again. Then, the production rate is set at $q_{1}$. Figure 5 illustrates the evolution of the process under this scenario. Figure 5(a) corresponds to the case where the duration of the CM action is shorter than $\frac{S}{q_{1}}$, hence no shortage occurrence. Contrarily, Figure 5(b) corresponds to the case where a shortage occurs when the duration of the CM action is longer than $\frac{S}{q_{1}}$. This scenario occurs at a probability calculated in Eq. (4):

$$
P\left(S_{4}\right)=\int_{0}^{T} \int_{0}^{x_{2}} f_{1}\left(x_{1}\right) \bar{F}_{3}\left(x_{1}\right) \frac{f_{2}\left(x_{2}\right)}{\bar{F}_{2}\left(x_{1}\right)} d x_{1} d x_{2} .
$$

\section{Development of the integrated model}

The described system consists of stochastic and independent identical cycles. The integrated model 


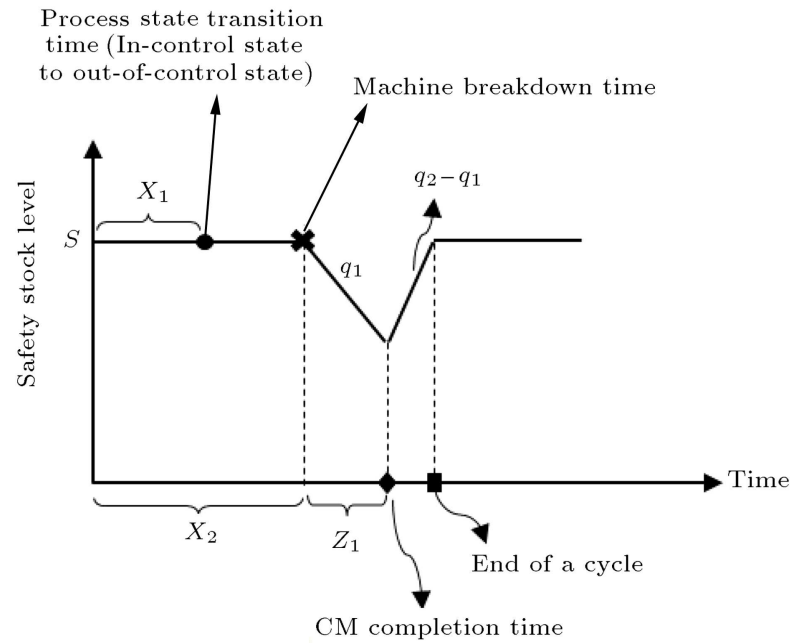

(a)

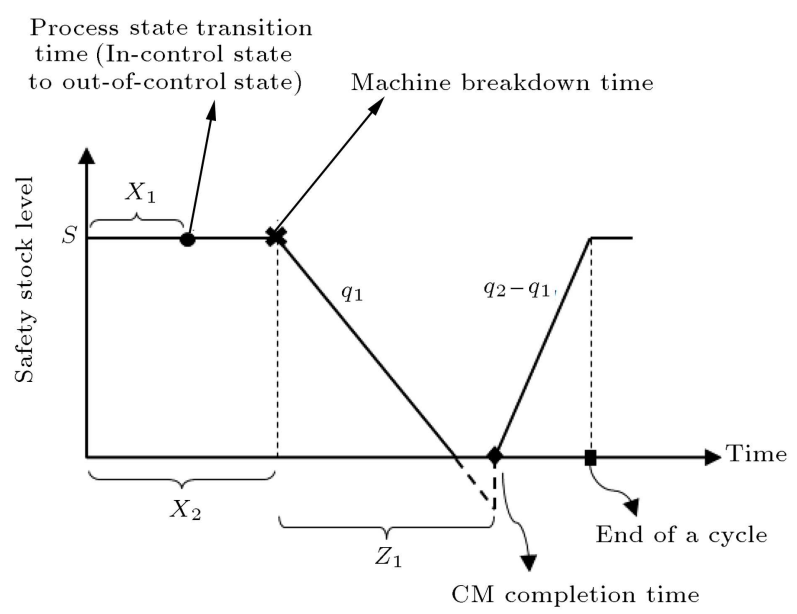

(b)

Figure 5. Evolution of the process corresponding to Scenario 4: (a) Without shortage and (b) with shortage.

is presented based on renewal reward process and recursive equations. The expected total cost of the system per unit of time is obtained through Eq. (5):

$$
E C T=\frac{E[T C]}{E[C L]},
$$

where $E[T C]$ is the expected total cost for each cycle and $E[C L]$ is the expected time length of that cycle. In addition, $E[T C]$ is the sum of the expected costs of maintenance $(E[M C])$, expected holding cost $(E[H C])$, expected shortage cost $(E[S H])$, expected warranty cost $(E[W R])$, and setup cost and it is calculated using Eq. (6):

$$
\begin{aligned}
E[T C]= & E[M C]+E[H C]+E[S H]+E[W R] \\
& +C_{\text {setup }} .
\end{aligned}
$$

According to the law of total expectation, Eq. (7) is derived to calculate $E[C L]$ as follows:

$$
\begin{aligned}
E[C L]= & P\left(S_{1}\right) E\left[C L \mid S_{1}\right]+P\left(S_{2}\right) E\left[C L \mid S_{2}\right] \\
& +P\left(S_{3}\right) E\left[C L \mid S_{3}\right]+P\left(S_{4}\right) E\left[C L \mid S_{4}\right],
\end{aligned}
$$

when the $i$ th scenario occurs at probability $P\left(S_{i}\right)$ and $i$ is equal to $1,2,3,4$. In addition, $E\left[C L \mid S_{i}\right]$ is the average time duration of the cycle.

In Scenario 1, $E\left[C L \mid S_{1}\right]$ is calculated through Eq. (8):

$$
\begin{aligned}
& E\left[C L \mid S_{1}\right]= \\
& \frac{\bar{F}_{1}(T) \bar{F}_{3}(T) \int_{0}^{\frac{s}{q_{1}}}\left(T+z_{2}+\frac{q_{1} z_{2}}{q_{2}-q_{1}}\right) g_{2}\left(z_{2}\right) d z_{2}}{P\left(S_{1}\right)} \\
& \quad+\frac{\bar{F}_{1}(T) \bar{F}_{3}(T) \int_{\frac{s}{q_{1}}}^{\infty}\left(T+z_{2}+\frac{s}{q_{2}-q_{1}}\right) g_{2}\left(z_{2}\right) d z_{2}}{P\left(S_{1}\right)} .
\end{aligned}
$$

In the first term of this equation, the average duration of a cycle is calculated while no shortage occurs. However, in the second term, the average time duration of a cycle is calculated where a shortage occurs.

In Scenario 2, $E\left[C L \mid S_{2}\right]$ is obtained through Eq. (9):

$$
\begin{aligned}
& E\left[C L \mid S_{2}\right]= \\
& \frac{\int_{0}^{T} \int_{0}^{\frac{s}{q_{1}}}\left(T+z_{2}+\frac{q_{1} z_{2}}{q_{2}-q_{1}}\right) g_{2}\left(z_{2}\right) f_{1}(x) \bar{F}_{3}(x) \frac{\bar{F}_{2}(T)}{\bar{F}_{2}(x)} d z_{2} d x}{P\left(S_{2}\right)} \\
& +\frac{\int_{0}^{T} \int_{\frac{s}{q_{1}}}^{\infty}\left(T+z_{2}+\frac{s}{q_{2}-q_{1}}\right) g_{2}\left(z_{2}\right) f_{1}(x) \bar{F}_{3}(x) \frac{\bar{F}_{2}(T)}{\bar{F}_{2}(x)} d z_{2} d x}{P\left(S_{2}\right)} .
\end{aligned}
$$

In the first term of this equation, the average time duration of a cycle is calculated while no shortage occurs. The second term calculates the average time duration of a cycle where a shortage occurs.

Under Scenario 3, $E\left[C L \mid S_{3}\right]$ is obtained through Eq. (10):

$$
\begin{aligned}
& E\left[C L \mid S_{3}\right]= \\
& \frac{\int_{0}^{T} \int_{0}^{\frac{s}{q_{1}}}\left(x+z_{1}+\frac{q_{1} z_{1}}{q_{2}-q_{1}}\right) g_{1}\left(z_{1}\right) f_{3}(x) \bar{F}_{1}(x) d z_{1} d x}{P\left(S_{3}\right)} \\
& +\frac{\int_{0}^{T} \int_{\frac{s}{q_{1}}}^{\infty}\left(x+z_{1}+\frac{s}{q_{2}-q_{1}}\right) g_{1}\left(z_{1}\right) f_{3}(x) \bar{F}_{1}(x) d z_{1} d x}{P\left(S_{3}\right)} .
\end{aligned}
$$

In the first term of this equation, the average time duration of a cycle is calculated with no shortage to occur. The second term calculates the average time duration of a cycle where a shortage occurs.

Under Scenario 4, $E\left[C L \mid S_{4}\right]$ is obtained through Eq. (11) as shown in Box I. In the first term of 


$$
\begin{aligned}
E\left[C L \mid S_{4}\right]= & \frac{\int_{0}^{T} \int_{0}^{x_{2}} \int_{0}^{\frac{s}{q_{1}}}\left(x_{2}+z_{1}+\frac{q_{1} z_{1}}{q_{2}-q_{1}}\right) g_{1}\left(z_{1}\right) f_{1}\left(x_{1}\right) \bar{F}_{3}\left(x_{1}\right) \frac{f_{2}\left(x_{2}\right)}{\bar{F}_{2}\left(x_{1}\right)} d z_{1} d x_{1} d x_{2}}{P\left(S_{4}\right)} \\
& +\frac{\int_{0}^{T} \int_{0}^{x_{2}} \int_{\frac{s}{q_{1}}}^{\infty}\left(x_{2}+z_{1}+\frac{s}{q_{2}-q_{1}}\right) g_{1}\left(z_{1}\right) f_{1}\left(x_{1}\right) \bar{F}_{3}\left(x_{1}\right) \frac{f_{2}\left(x_{2}\right)}{\bar{F}_{2}\left(x_{1}\right)} d z_{1} d x_{1} d x_{2}}{P\left(S_{4}\right)} .
\end{aligned}
$$

Box I

this equation, the average time duration of a cycle is calculated while no shortage occurs. The second term calculates the average duration of a cycle with a shortage to occur.

\subsection{Average cost of the maintenance action in each cycle}

The expected maintenance cost $(E[M C])$ is the sum of the expected costs of the PM implementation $(E[P M])$ and $\mathrm{CM}$ implementation $(E[C M])$. Once the PM action is conducted, if Scenario $S_{1}$ or $S_{2}$ occurs and the CM action is conducted while Scenario $S_{3}$ or $S_{4}$ occurs, Eqs. (12) and (13) are derived as follows:

$$
\begin{aligned}
E[P M]= & {\left[P\left(S_{1}\right)+P\left(S_{2}\right)-P\left(S_{1}\right) \cdot\left(S_{2}\right)\right] } \\
& \times C_{P M} \int_{0}^{\infty} z_{2} g_{2}\left(z_{2}\right) d z_{2}=\left[P\left(S_{1}\right)+P\left(S_{2}\right)\right. \\
& \left.-P\left(S_{1}\right) \cdot\left(S_{2}\right)\right] \times C_{P M} E\left[z_{2}\right] \\
E[C M]= & {\left[P\left(S_{3}\right)+P\left(S_{4}\right)-P\left(S_{3}\right) \cdot\left(S_{4}\right)\right] } \\
& \times C_{C M} \int_{0}^{\infty} z_{1} g_{1}\left(z_{1}\right) d z_{1}=\left[P\left(S_{3}\right)\right. \\
& \left.+P\left(S_{4}\right)-P\left(S_{3}\right) \cdot\left(S_{4}\right)\right] \times C_{C M} E\left[z_{1}\right] .
\end{aligned}
$$

\subsection{Average inventory holding cost in each cycle}

The average holding cost in each cycle is obtained through Eq. (14):

$$
\begin{aligned}
E[H C]= & P\left(S_{1}\right) E\left[H C \mid S_{1}\right] \\
& +P\left(S_{2}\right) E\left[H C \mid S_{2}\right] \\
& +P\left(S_{3}\right) E\left[H C \mid S_{3}\right]+P\left(S_{4}\right) E\left[H C \mid S_{4}\right],
\end{aligned}
$$

where $E\left[H C \mid S_{i}\right] ;(i=1,2,3,4)$ denotes the average holding costs if the $i$ th scenario is implemented.

In Scenario $1, E\left[H C \mid S_{1}\right]$ is obtained using Eq. (15) as shown in Box II. This equation consists of two terms. The first term calculates the average holding cost in case of no shortage, while the second term calculates it in case of a shortage.

In Scenario 2, $E\left[H C \mid S_{2}\right]$ is obtained through Eq. (16) as shown in Box III. This equation consists of two terms. The first term calculates the average holding cost when there is no shortage, while the second term calculates it in case of a shortage.

Under Scenario 3, $E\left[H C \mid S_{3}\right]$ is obtained through Eq. (17) as shown in Box IV. This equation consists of two terms. While the first term calculates the average holding cost in case of no shortage, the second term calculates it in case of a shortage.

Under scenario 4, $E\left[H C \mid S_{4}\right]$ is obtained by Eq. (18) as shown in Box V. This equation is composed of two terms: the first term calculates the average holding cost when there is no shortage, while the second term calculates the average holding cost when there is a shortage.

\subsection{Average shortage cost in each cycle}

The average shortage cost in each cycle is obtained through Eq. (19):

$$
\begin{aligned}
E\left[H C \mid S_{1}\right]= & \frac{C_{h}\left[\bar{F}_{1}(T) \bar{F}_{3}(T) \int_{0}^{\frac{S}{q_{1}}}\left\{s T+\left(z_{2}+\frac{q_{1} z_{2}}{q_{2}-q_{1}}\right) s-\frac{1}{2}\left(z_{2}+\frac{q_{1} z_{2}}{q_{2}-q_{1}}\right) q_{1} z_{2}\right\} g_{2}\left(z_{2}\right) d z_{2}\right]}{P\left(S_{1}\right)} \\
& +\frac{C_{h}\left[\left\{s T+\frac{s^{2}}{2 q_{1}}+\frac{s^{2}}{2\left(q_{2}-q_{1}\right)}\right\} \bar{G}_{2}\left(\frac{s}{q_{1}}\right) \bar{F}_{1}(T) \bar{F}_{3}(T)\right]}{P\left(S_{1}\right)}
\end{aligned}
$$




$$
\begin{aligned}
E\left[H C \mid S_{2}\right]= & \frac{C_{h}\left[\int_{0}^{T} \int_{0}^{\frac{s}{q_{1}}}\left\{s T+\left(z_{2}+\frac{q_{1} z_{2}}{q_{2}-q_{1}}\right) s-\frac{1}{2}\left(z_{2}+\frac{q_{1} z_{2}}{q_{2}-q_{1}}\right) q_{1} z_{2}\right\} f_{1}(x) \bar{F}_{3}(x) \frac{\bar{F}_{2}(T)}{\bar{F}_{2}(x)} g_{2}\left(z_{2}\right) d z_{2} d x\right]}{P\left(S_{2}\right)} \\
& +\frac{C_{h}\left[\int_{0}^{T}\left\{s T+\frac{s^{2}}{2 q_{1}}+\frac{s^{2}}{2\left(q_{2}-q_{1}\right)}\right\} \bar{G}_{2}\left(\frac{s}{q_{1}}\right) f_{1}(x) \bar{F}_{3}(x) \frac{\bar{F}_{2}(T)}{\bar{F}_{2}(x)} d x\right]}{P\left(S_{2}\right)} .
\end{aligned}
$$

Box III

$$
\begin{aligned}
E\left[H C \mid S_{3}\right]= & \frac{C_{h}\left[\int_{0}^{T} \int_{0}^{\frac{S}{q_{1}}}\left\{s x+\left(z_{1}+\frac{q_{1} z_{1}}{q_{2}-q_{1}}\right) s-\frac{1}{2}\left(z_{1}+\frac{q_{1} z_{1}}{q_{2}-q_{1}}\right) q_{1} z_{1}\right\} f_{3}(x) \bar{F}_{1}(x) g_{1}\left(z_{1}\right) d z_{1} d x\right]}{P\left(S_{3}\right)} \\
& +\frac{C_{h}\left[\int_{0}^{T}\left\{s x+\frac{s^{2}}{2 q_{1}}+\frac{s^{2}}{2\left(q_{2}-q_{1}\right)}\right\} \bar{G}_{1}\left(\frac{s}{q_{1}}\right) f_{3}(x) \bar{F}_{1}(x) d x\right]}{P\left(S_{3}\right)} .
\end{aligned}
$$

Box IV

$$
\begin{aligned}
E[S H]= & P\left(S_{1}\right) E\left[S H \mid S_{1}\right]+P\left(S_{2}\right) E\left[S H \mid S_{2}\right] \\
& +P\left(S_{3}\right) E\left[S H \mid S_{3}\right]+P\left(S_{4}\right) E\left[S H \mid S_{4}\right],
\end{aligned}
$$

where $E\left[S H \mid S_{i}\right],(i=1,2,3,4)$, denotes the average shortage costs in case the $i$ th scenario is implemented.

In Scenario 1, $E\left[S H \mid S_{1}\right]$ can be obtained using Eq. (20):

$E\left[S H \mid S_{1}\right]=\frac{C_{s}\left[\bar{F}_{1}(T) \bar{F}_{3}(T) \int_{\frac{S}{q_{1}}}^{\infty}\left(q_{1} z_{2}-s\right) g_{2}\left(z_{2}\right) d z_{2}\right]}{P\left(S_{1}\right)}$.

In Scenario 2, $E\left[S H \mid S_{2}\right]$ is obtained using Eq. (21):

$$
\begin{aligned}
& E\left[S H \mid S_{2}\right]= \\
& \frac{C_{s}\left[\int_{0}^{T} \int_{\frac{S}{q_{1}}}^{\infty}\left(q_{1} z_{2}-s\right) g_{2}\left(z_{2}\right) f_{1}(x) \bar{F}_{3}(x) \frac{\bar{F}_{2}(T)}{\bar{F}_{2}(x)} d z_{2} d x\right]}{P\left(S_{2}\right)} .
\end{aligned}
$$

Under Scenario 3, $E\left[S H \mid S_{3}\right]$ is computed using Eq. (22):

$$
\begin{aligned}
& E\left[S H \mid S_{3}\right]= \\
& \frac{C_{s}\left[\int_{0}^{T} \int_{\frac{S}{q_{1}}}^{\infty}\left(q_{1} z_{1}-s\right) g_{1}\left(z_{1}\right) f_{3}(x) \bar{F}_{1}(x) d z_{1} d x\right]}{P\left(S_{3}\right)} .
\end{aligned}
$$

Under Scenario 4, $E\left[S H \mid S_{4}\right]$ is calculated through Eq. (23) as shown in Box VI.

\subsection{Average warranty cost in each cycle}

The average number of the defective items that may be detected in the warranty period can be obtained based on Eq. (24):

$$
\int_{0}^{w} E[N] h(k) d k
$$

Therefore, the average warranty cost in each cycle can be obtained from Eq. (25):

$$
E[W R]=C_{w} \int_{0}^{w} E[N] h(k) d k .
$$

$$
\begin{aligned}
E\left[H C \mid S_{4}\right]= & \frac{C_{h}\left[\int_{0}^{T} \int_{0}^{x_{2}} \int_{0}^{\frac{s}{q_{1}}}\left\{s x_{2}+\left(z_{1}+\frac{q_{1} z_{1}}{q_{2}-q_{1}}\right) s-\frac{1}{2}\left(z_{1}+\frac{q_{1} z_{1}}{q_{2}-q_{1}}\right) q_{1} z_{1}\right\} g_{1}\left(z_{1}\right) f_{1}\left(x_{1}\right) \bar{F}_{3}\left(x_{1}\right) \frac{f_{2}\left(x_{2}\right)}{\bar{F}_{2}\left(x_{1}\right)} d z_{1} d x_{1} d x_{2}\right]}{P\left(S_{4}\right)} \\
& +\frac{C_{h}\left[\int_{0}^{T} \int_{0}^{x_{2}} \int_{\frac{S}{q_{1}}}^{\infty}\left\{s x_{2}+\frac{s^{2}}{2 q_{1}}+\frac{s^{2}}{2\left(q_{2}-q_{1}\right)}\right\} g_{1}\left(z_{1}\right) f_{1}\left(x_{1}\right) \bar{F}_{3}\left(x_{1}\right) \frac{f_{2}\left(x_{2}\right)}{\bar{F}_{2}\left(x_{1}\right)} d z_{1} d x_{1} d x_{2}\right]}{P\left(S_{4}\right)}
\end{aligned}
$$




$$
E\left[S H \mid S_{4}\right]=\frac{C_{s}\left[\int_{0}^{T} \int_{0}^{x_{2}} \int_{\frac{s}{q_{1}}}^{\infty}\left(q_{1} z_{1}-s\right) g_{1}\left(z_{1}\right) f_{1}\left(x_{1}\right) \bar{F}_{3}\left(x_{1}\right) \frac{f_{2}\left(x_{2}\right)}{\bar{F}_{2}\left(x_{1}\right)} d z_{1} d x_{1} d x_{2}\right]}{P\left(S_{4}\right)} .
$$

\section{Box VI}

The average number of defective products in state 1 in a cycle is obtained from Eq. (26):

$$
E[N]=P\left(S_{2}\right) E\left[N \mid S_{2}\right]+P\left(S_{4}\right) E\left[N \mid S_{4}\right] .
$$

As mentioned before, defective items may be produced in state 1 . In Eq. (26), $E\left[N \mid S_{i}\right]$ denotes the average number of defective products in state 1 under Scenarios 2 and 4 .

Under Scenario 2, $E\left[N \mid S_{2}\right]$ is obtained by Eq. (27):

$$
E\left[N \mid S_{2}\right]=\frac{q_{1} P\left[\int_{0}^{T}(T-x) f_{1}(x) \bar{F}_{3}(x) \frac{\bar{F}_{2}(T)}{\bar{F}_{2}(x)} d x\right]}{P\left(S_{2}\right)} .
$$

Under Scenario 4, $E\left[N \mid S_{4}\right]$ is computed using Eq. (28):

$$
\begin{aligned}
& E\left[N \mid S_{4}\right]= \\
& \frac{q_{1} P\left[\int_{0}^{T} \int_{0}^{x_{2}}\left(x_{2}-x_{1}\right) f_{1}\left(x_{1}\right) \bar{F}_{3}\left(x_{1}\right) \frac{f_{2}\left(x_{2}\right)}{F_{2}\left(x_{1}\right)} d x_{1} d x_{2}\right]}{P\left(S_{4}\right)} .
\end{aligned}
$$

\section{Numerical study}

\subsection{Numerical example}

In this section, a numerical example is solved to verify the efficiency of the model. Due to the complexity of the equations of the integrated model, the exact methods are not effective in solving the model. Therefore, the model was first solved using a grid search algorithm. Since the runtime of the grid search is not acceptable, a genetic algorithm was coded using the MATLAB software to optimize the model. The genetic algorithm is a meta-heuristic method for solving complex problems. It is inspired by the process of natural selection. The algorithm is commonly used to generate high-quality solutions to optimization problems and it is also applied to many scientific subjects such as operation research and computer science $[25,26]$.

To perform a numerical study in this section, it is assumed that the times of process state transitions from the in-control state to an out-of-control state $\left(x_{1}\right)$, from the out-of-control state to machine breakdown $\left(x_{2}\right)$, and from the in-control state to machine breakdown $\left(x_{3}\right)$ are based on the Weibull distribution with the probability density functions presented in Eqs. (29), (30), and (31), respectively:

$$
\begin{gathered}
f_{1}\left(x_{1}\right)=\lambda_{1} v_{1}\left(\lambda_{1} x_{1}\right)^{v_{1}-1} e^{-\left(\lambda_{1} x_{1}\right)^{v_{1}}} ; \\
x_{1} \geq 0, \quad \lambda_{1} \geq 0, \quad v_{1} \geq 1, \\
f_{2}\left(x_{2}\right)=\lambda_{2} v_{2}\left(\lambda_{2} x_{2}\right)^{v_{2}-1} e^{-\left(\lambda_{2} x_{2}\right)^{v_{2}}} ; \\
x_{2} \geq 0, \quad \lambda_{2} \geq 0, \quad v_{2} \geq 1, \\
f_{3}\left(x_{3}\right)=\lambda_{3} v_{3}\left(\lambda_{3} x_{3}\right)^{v_{3}-1} e^{-\left(\lambda_{3} x_{3}\right)^{v_{3}}} ; \\
x_{3} \geq 0, \quad \lambda_{3} \geq 0, \quad v_{3} \geq 1 .
\end{gathered}
$$

It is also assumed that the CM time $\left(z_{1}\right)$ and $\mathrm{PM}$ time $\left(z_{2}\right)$ follow the Weibull distribution with the probability density functions presented in Eqs. (32) and (33), respectively:

$$
\begin{gathered}
g_{1}\left(z_{1}\right)=\gamma_{1} \theta_{1}\left(\gamma_{1} z_{1}\right)^{\theta_{1}-1} e^{-\left(\gamma_{1} z_{1}\right)^{\theta_{1}}} ; \\
z_{1} \geq 0, \quad \gamma_{1} \geq 0, \quad \theta_{1} \geq 1, \\
g_{2}\left(z_{2}\right)=\gamma_{2} \theta_{2}\left(\gamma_{2} z_{2}\right)^{\theta_{2}-1} e^{-\left(\gamma_{2} z_{2}\right)^{\theta_{2}}} ; \\
z_{2} \geq 0, \quad \gamma_{2} \geq 0, \quad \theta_{2} \geq 1 .
\end{gathered}
$$

Moreover, the lifetime of non-conforming items is assumed to be based on the Weibull distribution with the probability density function presented in Eq. (34):

$$
h(k)=\frac{k}{18} e^{-\left(\frac{k}{6}\right)^{2}} .
$$

The data given in [5] is mostly used to study the example. Table 2 lists the data used in this study. The values of the Weibull distributions parameters are as follows:

$$
\begin{aligned}
& \lambda_{1}=0.3, \quad \lambda_{2}=0.3, \quad \lambda_{3}=0.3, \\
& v_{1}=2, \quad v_{2}=2, \quad v_{3}=2,
\end{aligned}
$$

Table 2. The values of the input parameters.

\begin{tabular}{cccccccccc}
\hline $\boldsymbol{q}_{\boldsymbol{1}}$ & $\boldsymbol{q}_{\boldsymbol{2}}$ & $\boldsymbol{P}$ & $\boldsymbol{C}_{\boldsymbol{h}}$ & $\boldsymbol{C}_{\boldsymbol{s}}$ & $\boldsymbol{C}_{\boldsymbol{C} \boldsymbol{M}}$ & $\boldsymbol{C}_{\boldsymbol{P} \boldsymbol{M}}$ & $\boldsymbol{C}_{\boldsymbol{w}}$ & $\boldsymbol{W}$ & $\boldsymbol{C}_{\text {setup }}$ \\
\hline 90 & 160 & 0.3 & 0.2 & 0.8 & 50 & 5 & 20 & 1 & 300 \\
\hline
\end{tabular}


Table 3. The values of the GA parameters.

\begin{tabular}{ccccc}
\hline Generation number & Population size & Crossover rate & Mutation rate & cm \\
\hline 100 & 30 & 0.4 & 0.1 & 0.2 \\
\hline
\end{tabular}

Table 4. The optimal values of the decision variables and ECT.

\begin{tabular}{ccc}
\hline $\boldsymbol{T}^{*}$ & $\boldsymbol{S}^{*}$ & $\boldsymbol{E} \boldsymbol{C} \boldsymbol{T}$ \\
\hline 2.7467 & 131 & 81.4075 \\
\hline
\end{tabular}

Table 5. The comparison of the obtained results.

\begin{tabular}{ccc}
\hline & $\begin{array}{c}\boldsymbol{E C T} \\
\text { (our model) }\end{array}$ & $\begin{array}{c}\boldsymbol{E} \boldsymbol{C T} \\
\text { (Ref. [5]) }\end{array}$ \\
\hline$\lambda_{1}=0.1, \lambda_{2}=0.25$ & 101.4399 & 96.8037 \\
$\lambda_{1}=0.3, \lambda_{2}=0.25$ & 108.0275 & 97.0267 \\
$\lambda_{1}=0.5, \lambda_{2}=0.25$ & 114.0605 & 97.3386 \\
$\lambda_{1}=0.7, \lambda_{2}=0.25$ & 114.9084 & 97.6490 \\
& & \\
$\lambda_{1}=0.5, \lambda_{2}=0.1$ & 93.1943 & 88.0799 \\
$\lambda_{1}=0.5, \lambda_{2}=0.2$ & 98.8950 & 95.4210 \\
$\lambda_{1}=0.5, \lambda_{2}=0.3$ & 106.2644 & 98.5072 \\
$\lambda_{1}=0.5, \lambda_{2}=0.4$ & 108.90 & 99.7307 \\
$\lambda_{1}=0.5, \lambda_{2}=0.5$ & 111.6721 & 100.295 \\
\hline & & \\
$\gamma_{1}=0.4, \quad \gamma_{2}=0.4$, & & \\
$\theta_{1}=2, \quad \theta_{2}=2$. & &
\end{tabular}

Table 3 presents the parameters of the genetic algorithm used for optimization. Table 4 lists the optimal values of $T, S$, and $E C T$. Accordingly, the optimal value of the safety stock level is 131 , and it is recommended that PM action be taken after 2.7467 time units pass from the start of the production cycle. Through this policy, the expected total cost per time unit is optimized, the value of which is calculated as 81.4075 .

To validate the results obtained from the genetic algorithm, they were compared with those obtained from the optimization algorithm proposed in [5]. In the referenced study, a computational algorithm was proposed to reach a global optimum. The integrated model proposed in the present study was solved by the genetic algorithm with different values of $\lambda_{1}$ and $\lambda_{2}$ while the other parameters remain constant. The results are compared with those obtained in [5]. The obtained solutions are presented in Table 5 .

The comparison of the obtained results reveals that there is a minor difference between the optimal values of the objective function $(E C T)$ in the proposed model and the one in [5]. Therefore, it can be concluded that the solutions obtained through the genetic algorithm in this study are nearly optimal. In addition,

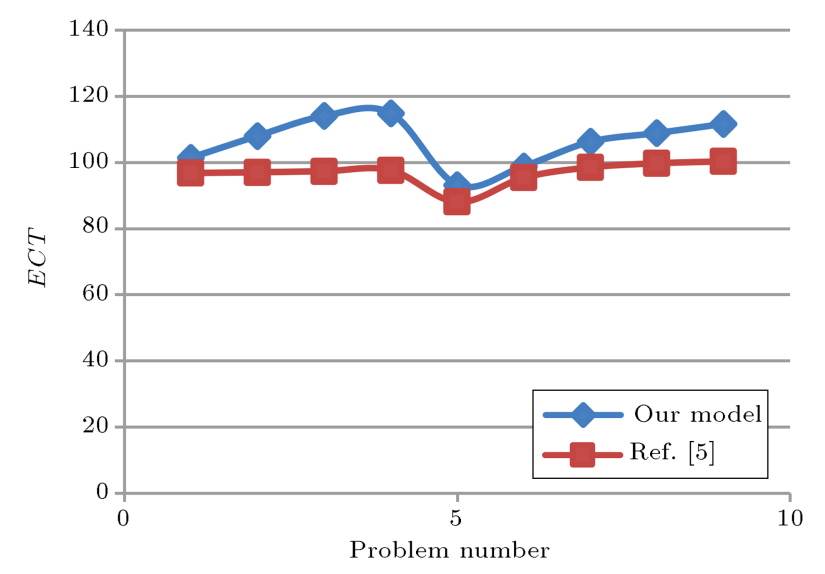

Figure 6. The comparison of the optimal values of $E C T$ in our model and Ref. [5].

Table 6. The results obtained for $\lambda_{1}$.

\begin{tabular}{cccc}
\hline $\boldsymbol{\lambda}_{\mathbf{1}}$ & $\boldsymbol{T}$ & $\boldsymbol{S}$ & $\boldsymbol{E} \boldsymbol{C} \boldsymbol{T}$ \\
\hline 0.1 & 7.076 & 115.765 & 90.2431 \\
0.2 & 5.856 & 126.125 & 113.975 \\
0.35 & 5.2825 & 131.405 & 122.805 \\
0.4 & 3.0086 & 189.462 & 187.4 \\
0.5 & 1.8288 & 194.146 & 194.111 \\
\hline
\end{tabular}

it indicates the efficiency of the proposed model and validity of the solutions obtained through the genetic algorithm. Figure 6 presents the comparison results.

\subsection{Sensitivity analysis}

In this section, a sensitivity analysis of the critical parameters is done to identify their effects on the decision variables and total cost.

The effects of the change of $\lambda_{1}$ on the decision variables and ECT are shown in Table 6 as well as Figures 7, 8, and 9. The results obtained from the genetic algorithm indicate that larger values of $\lambda_{1}$ lead to a reduction in the optimal value of $T$ and an increase in the optimal values of the safety stock and $E C T$ mainly because an increase in $\lambda_{1}$ would increase the probability of the process shift from state 0 to state 1 as well as the probability of producing defective items. Consequently, the minimal repair cost increases during the warranty period. In addition, an increase in $\lambda_{1}$ would increase the safety stock level to avoid shortage. Moreover, the expected holding cost increases with an increase in the value of $S$. Therefore, in case the holding and minimal repair costs increase, the $E C T$ would consequently increase. At larger values of $\lambda_{1}$, the optimal value of $T$ decreases to reduce the probability 


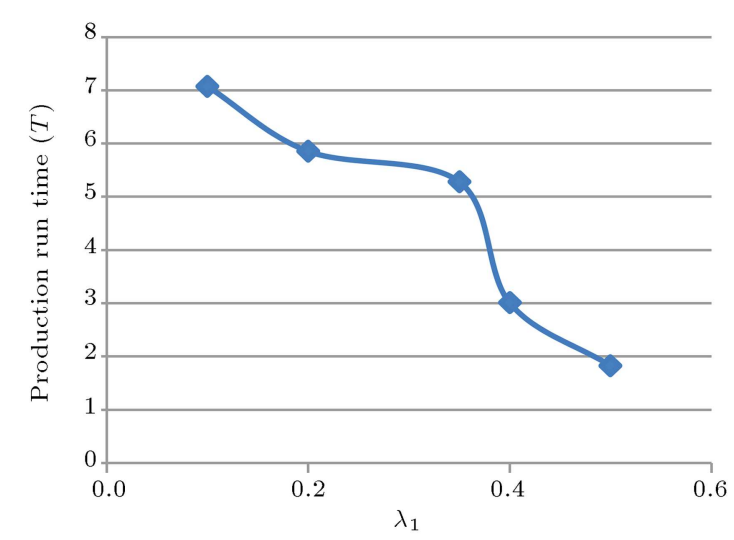

Figure 7. The effect of $\lambda_{1}$ on the production run time $(T)$.

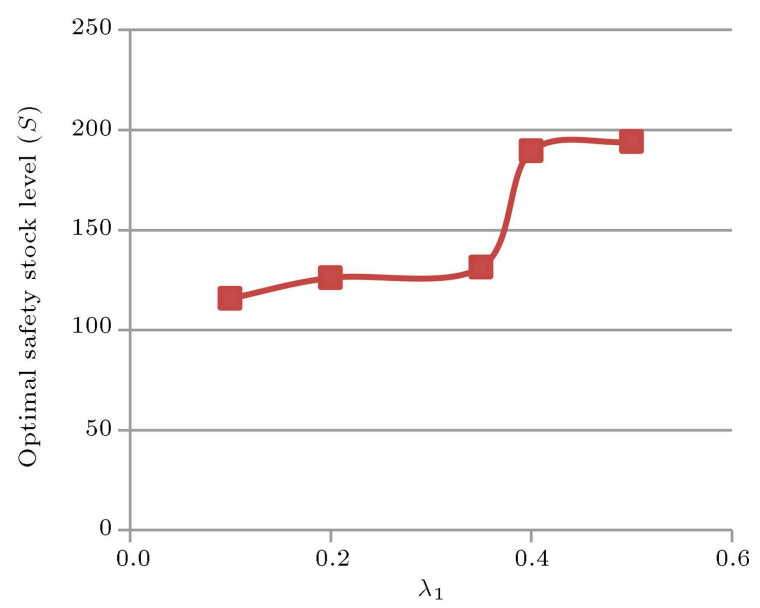

Figure 8. The effect of $\lambda_{1}$ on the optimal safety stock level $(S)$.

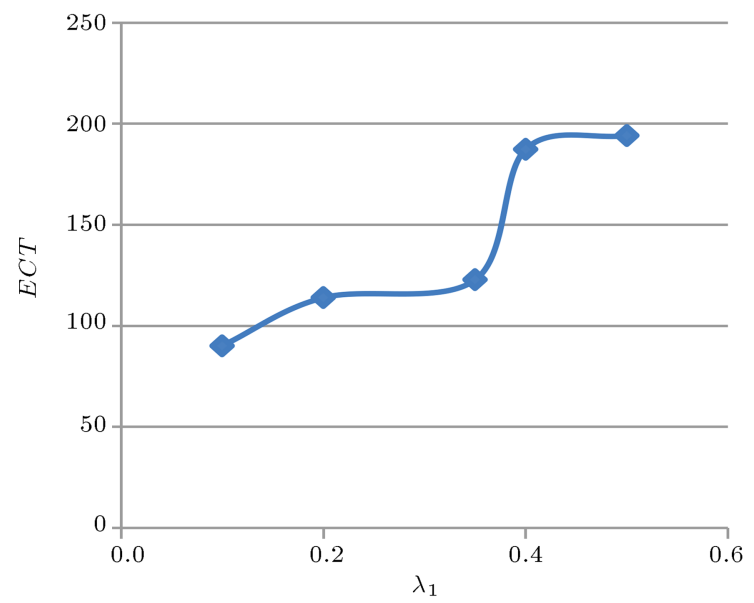

Figure 9. The effect of $\lambda_{1}$ on ECT.

of the process shift from state 0 to state 1 and reduce the average number of the defective items in state 1.

The effects of a change in both $\lambda_{2}$ and $\lambda_{3}$ on the decision variables and ECT are given in Table 7 and Figures 10-15. Larger values of $\lambda_{2}$ and $\lambda_{3}$ would lead to a decrease in the value of $T$ and an increase in the optimal values of the safety stock and ECT. With
Table 7. The results obtained for $\lambda_{2}$ and $\lambda_{3}$.

\begin{tabular}{ccccc}
\hline & & $\boldsymbol{T}$ & $\boldsymbol{S}$ & $\boldsymbol{E C} \boldsymbol{T}$ \\
\hline \multirow{4}{*}{$\lambda_{2}$} & 0.1 & 5.8527 & 45.5386 & 87.3224 \\
& 0.2 & 4.7798 & 71.5818 & 96.706 \\
& 0.35 & 2.7741 & 138.119 & 98.7942 \\
& 0.4 & 1.1537 & 155.811 & 132.621 \\
& 0.5 & 0.7874 & 165.61 & 160.53 \\
& & & & \\
& 0.1 & 9.8834 & 41.4498 & 108.383 \\
$\lambda_{3}$ & 0.2 & 7.1648 & 81.5902 & 110.877 \\
& 0.35 & 5.2074 & 85.6166 & 120.228 \\
& 0.4 & 4.9811 & 120.191 & 128.292 \\
& 0.5 & 2.0696 & 183.79 & 193.979 \\
\hline
\end{tabular}

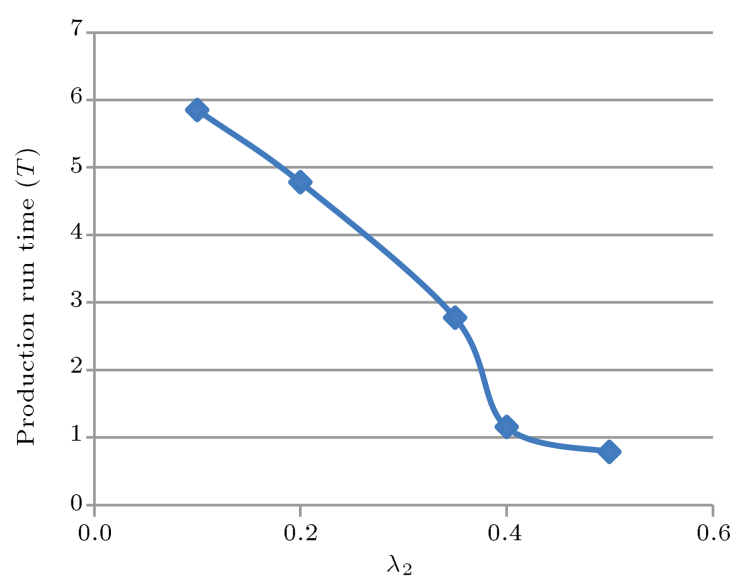

Figure 10. The effect of $\lambda_{2}$ on the production run time $(T)$.

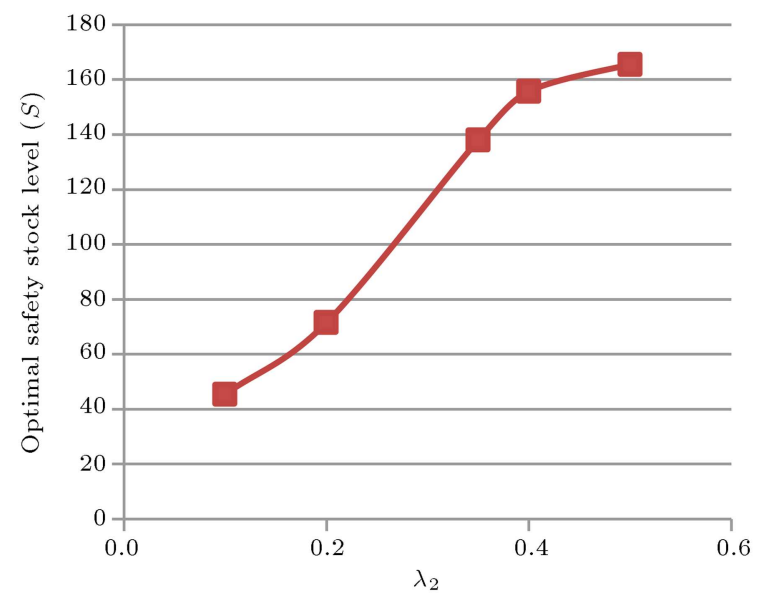

Figure 11. The effect of $\lambda_{2}$ on the optimal safety stock level $(S)$.

larger values of $\lambda_{2}$ and $\lambda_{3}$, the value of $T$ decreases to reduce the probability of machine failure. In addition, as the values of $\lambda_{2}$ and $\lambda_{3}$ increase, the safety stock level increases as well to avoid possible stock-out during the performance of maintenance actions. Due to an increase in the failure rate, the maintenance cost 


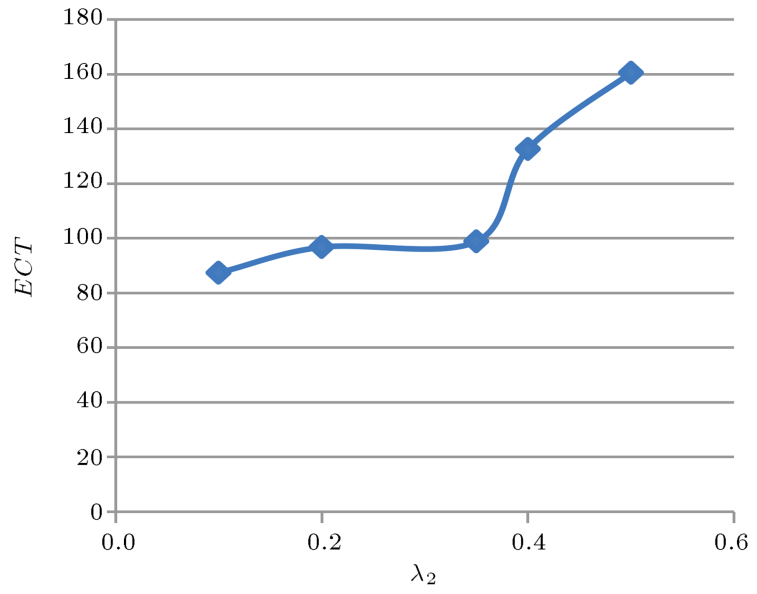

Figure 12. The effect of $\lambda_{2}$ on $E C T$.

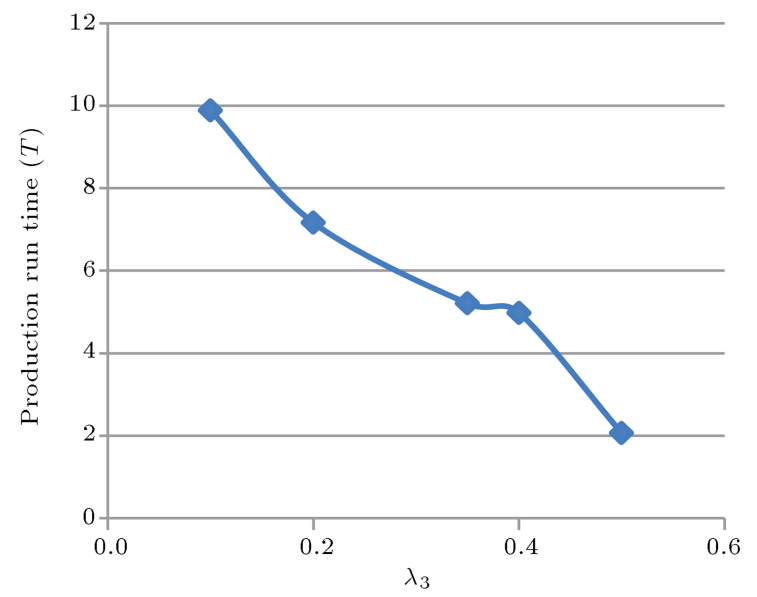

Figure 13. The effect of $\lambda_{3}$ on the production run time $(T)$.

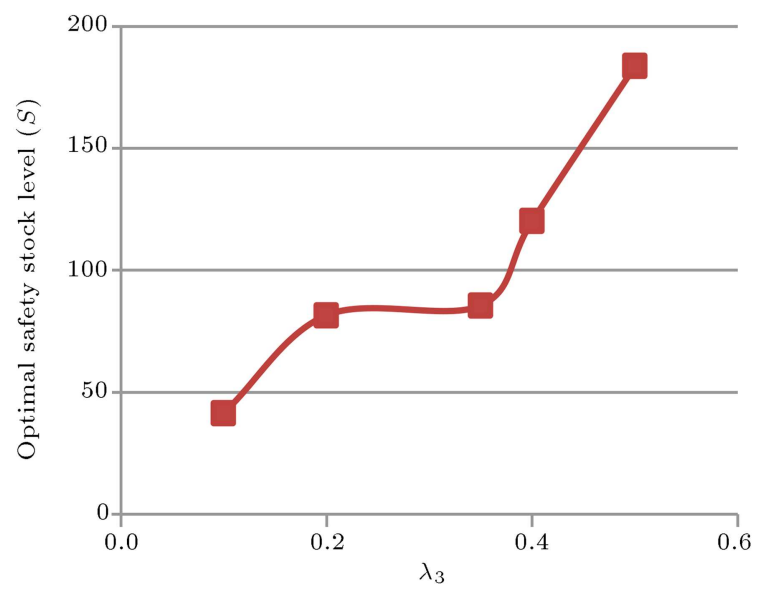

Figure 14. The effect of $\lambda_{3}$ on the optimal safety stock level $(S)$.

increases, and an increase in the safety stock level leads to a rise in the holding cost and consequently $E C T$.

Larger values of $\lambda_{1}$ and $\lambda_{2}$ would increase the optimal value of $S$ to avoid possible stock-out and meet the demand during the CM and PM actions. The obtained results are presented in Table 8 and Figure 16.

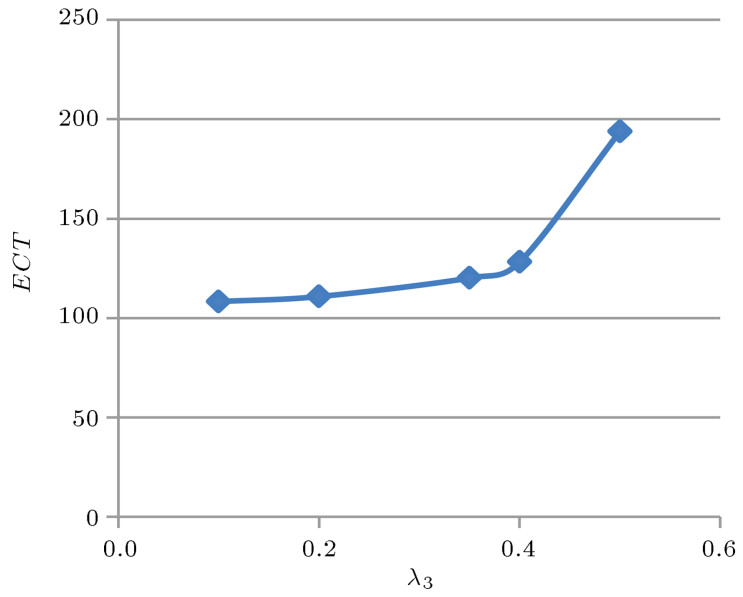

Figure 15. The effect of $\lambda_{3}$ on $E C T$.
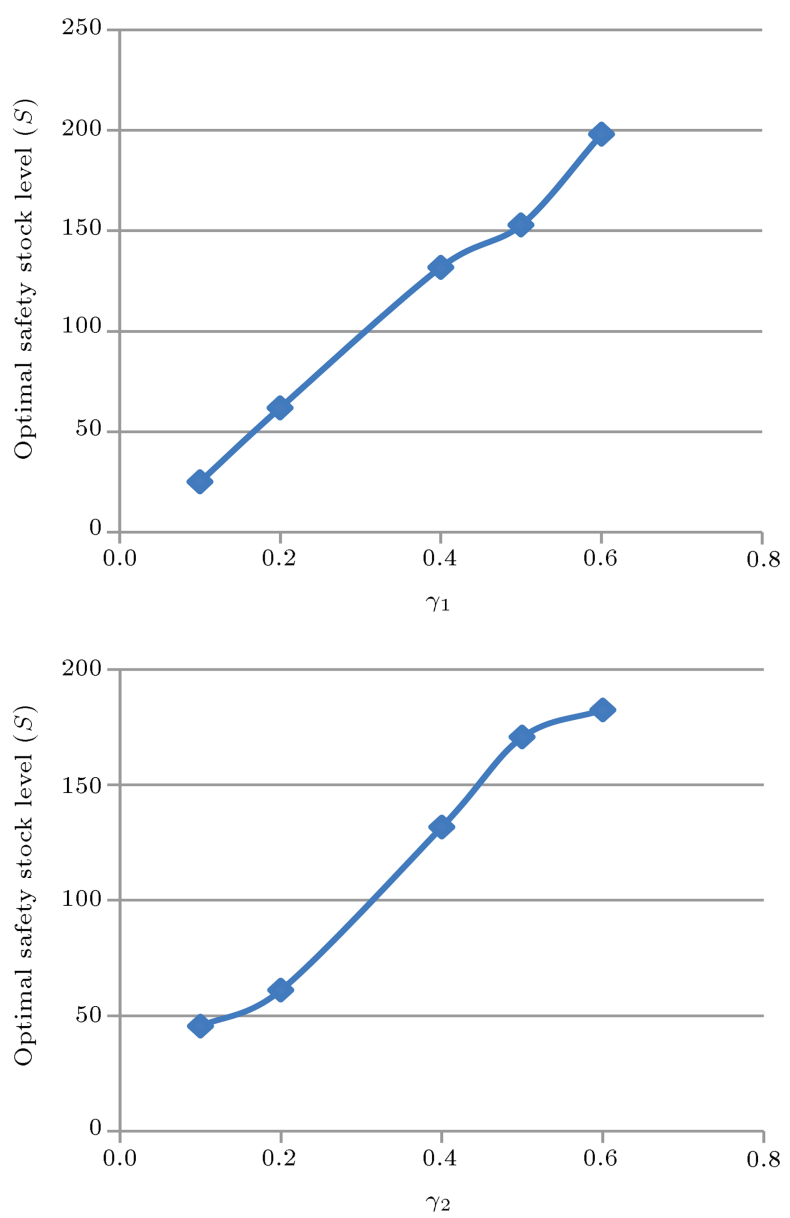

Figure 16. The effects of $\gamma_{1}$ and $\gamma_{2}$ on the optimal safety stock level.

An increase in the PM cost leads to a decrease in the safety stock level while an increase in the CM cost causes an increase in the safety stock level. Table 9 and Figure 17 present the obtained results.

Larger values of the holding cost decrease the value of $S$. In addition, an increase in the shortage cost causes an increase in the value of $S$. Table 10 and Figure 18 list the obtained results. 
Table 8. The results obtained for $\gamma_{1}$ and $\gamma_{2}$.

\begin{tabular}{|c|c|c|c|c|c|c|c|c|c|c|}
\hline & \multicolumn{5}{|c|}{$\gamma_{1}$} & \multicolumn{5}{|c|}{$\gamma_{2}$} \\
\hline & 0.1 & 0.2 & 0.4 & 0.5 & 0.6 & 0.1 & 0.2 & 0.4 & 0.5 & 0.6 \\
\hline$S$ & 25.03 & 61.92 & 131.85 & 152.88 & 198.08 & 45.53 & 61.12 & 131.85 & 170.72 & 182.56 \\
\hline
\end{tabular}

Table 9. The results obtained for $C_{P M}$ and $C_{C M}$.

\begin{tabular}{|c|c|c|c|c|c|c|c|c|c|c|}
\hline & \multicolumn{5}{|c|}{$C_{P M}$} & \multicolumn{5}{|c|}{$C_{C M}$} \\
\hline & 2 & 5 & 10 & 15 & 20 & 20 & 30 & 50 & 70 & 100 \\
\hline$S$ & 179.75 & 131.85 & 119.96 & 91.85 & 57.61 & 61.79 & 125.56 & 131.85 & 152.31 & 174.87 \\
\hline
\end{tabular}

Table 10. The results obtained for $C_{h}$ and $C_{S}$.

\begin{tabular}{cccccccccccc}
\hline \multicolumn{1}{c}{$\boldsymbol{C}_{\boldsymbol{h}}$} \\
\hline & 0.1 & 0.3 & 0.5 & 0.6 & 0.7 & 0.8 & 1 & 2 & 3 & 4 & 5 \\
$S$ & 181.62 & 142.74 & 130.79 & 113.19 & 56.57 & 131.85 & 166.78 & 187.07 & 188.03 & 188.46 & 198.16 \\
\hline
\end{tabular}
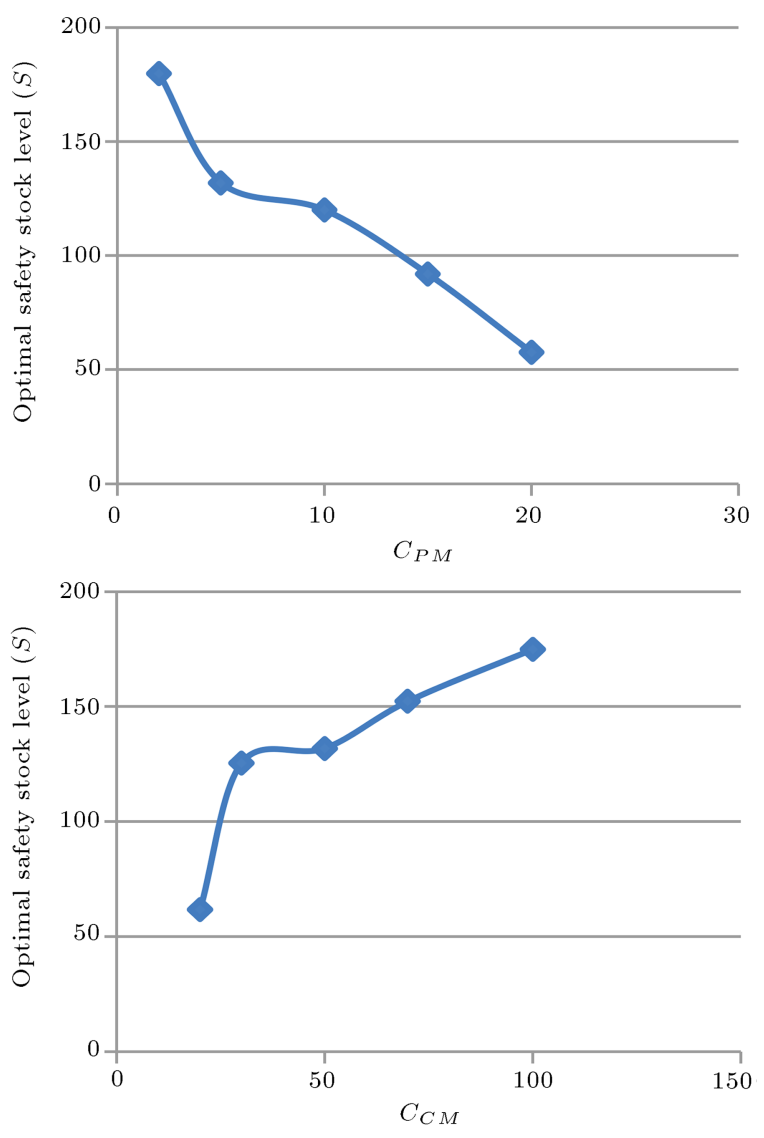

Figure 17. The effects of $C_{P M}$ and $C_{C M}$ on the optimal safety stock level.

An increase in the value of $P$ decreases the optimal value of $T$ and increases the optimal values of $S$ and $E C T$. With the larger values of $P$, the value of $T$ decreases to reduce the number of the defective products in state 1 . As the value of $P$ rises, the optimal value of $S$ rises as well to avoid shortage. Moreover, an increase in the value of $P$ leads to an increase in the
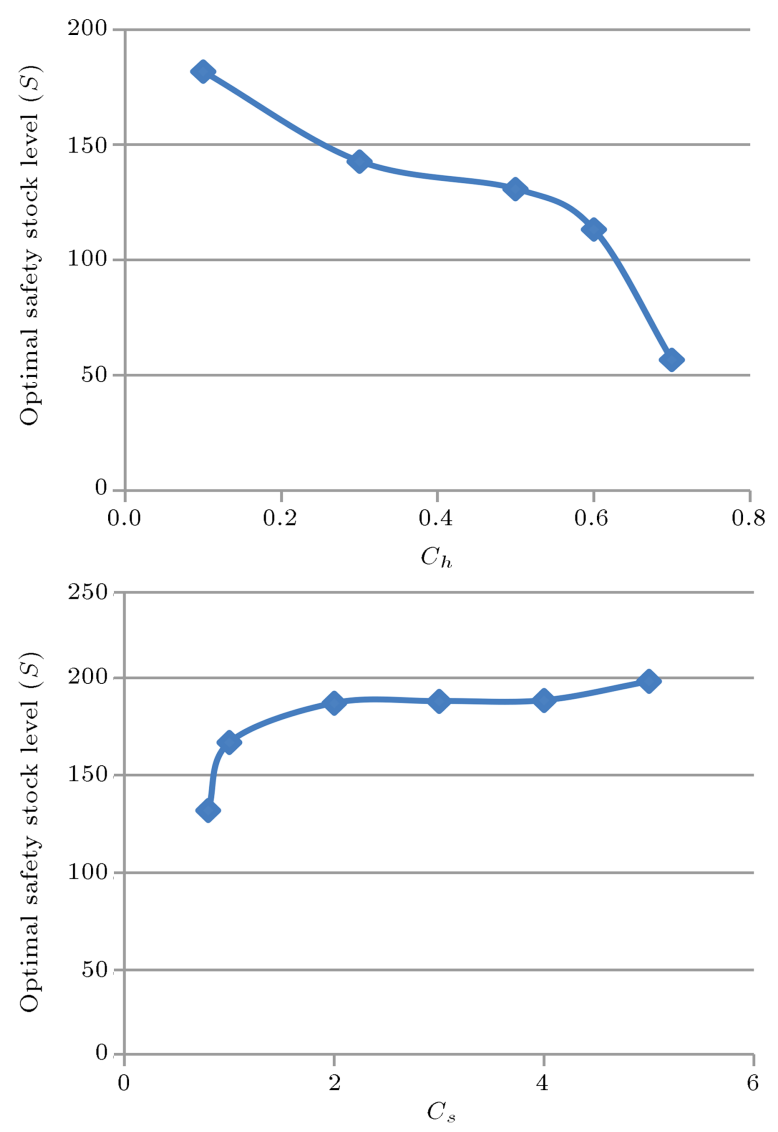

Figure 18. The effects of $C_{h}$ and $C_{S}$ on the optimal safety stock level.

possibility of producing defective products. As a result, the repair cost during the warranty period increases. As a result of an increase in the safety stock level, the expected holding cost would also increase. These two increased values will in turn increase the value of $E C T$. The obtained results are presented in Table 11 as well as Figures 19 and 20. 
Table 11. The results obtained for $P$.

\begin{tabular}{cccc}
\hline $\boldsymbol{P}$ & $\boldsymbol{T}$ & $\boldsymbol{S}$ & $\boldsymbol{E C T}$ \\
\hline 0.2 & 3.9819 & 129.592 & 80.9773 \\
0.3 & 2.7467 & 131.855 & 81.4075 \\
0.4 & 2.4187 & 136.703 & 86.0378 \\
0.5 & 1.8222 & 162.73 & 89.1744 \\
0.7 & 1.0937 & 170.223 & 93.541 \\
\hline
\end{tabular}
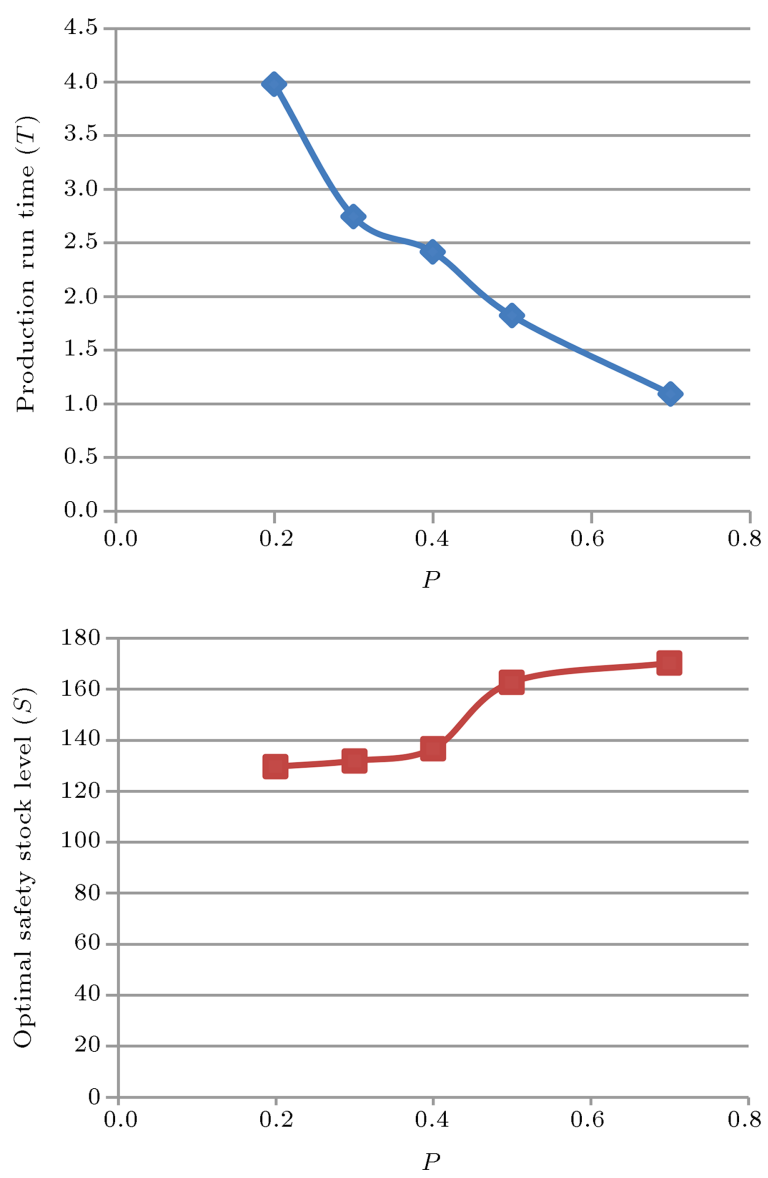

Figure 19. The effect of $P$ on the decision variables.

\section{Conclusion}

In this study, a mathematical model was presented for joint planning of maintenance and inventory control in a deteriorating production system. The process deteriorated and underwent two operational states and a failure mode. The transitions among the states of the process were based on general continuous random variables. Both Preventive Maintenance (PM) and Corrective Maintenance (CM) actions were taken during each production cycle. The time duration to take maintenance actions was considered to be a continuous random variable. The proposed model primarily aimed to integrate the decisions on how to determine the optimal safety stock level and time to

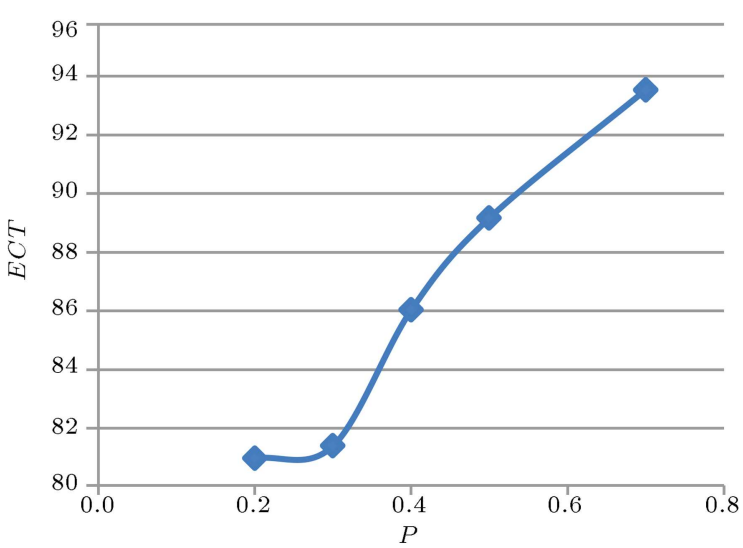

Figure 20. The effect of $P$ on $E C T$.

perform maintenance actions to finally minimize the expected total cost of the process. In this regard, a numerical study was carried out and a series of sensitivity analyses of some important parameters were done. Due to the complexity of the proposed integrated model, the genetic algorithm was used for optimization and the solutions were validated. The results indicated the acceptable performance of the model in real-world situations. All the products were sold with a free minimal repair warranty. The modeling system described in this study can be used in real-world situations such as the automobile industry. Car manufacturers and car dealers specify warranty periods to win and retain customers, mainly because some non-conforming items in cars are operational, meaning that they can be detected after a period of use.

The managers in manufacturing systems can make dynamic and ideal plans for their production processes by joint planning of maintenance, production, and quality control. Machinery, human resources, and other production aspects were taken into consideration in an optimal manner and the productivity of the production process was eventually improved by integrated planning. The integrated model can be of benefit in manufacturing systems with the JIT (Just In Time) policy. In such systems, the products are produced based on demand level and the managers peruse the objective of eliminating inventory. In this respect, the integrated model made it possible to jointly deal with production plans, maintenance schedules, and quality control policies considering the demand level and production capacity. The integrated models can also be employed in continuous manufacturing systems. In such systems, the process should operate without interruptions during the production process. Here, optimal planning for production, maintenance scheduling, and quality control gains significance. Of note, the efficiency of production processes can be improved using an integrated model that enables the joint planning of production, maintenance, and quality control. 
Different quality control policies such as acceptance sampling plans or $100 \%$ inspection policies can be formulated to detect defective items during production processes in future research. The insights provided by this study may be taken into consideration to develop an integrated model for different manufacturing systems such as multi-machine manufacturing systems, multi-stage systems, and series production systems.

\section{References}

1. Lopes, R. "Integrated model of quality inspection, preventive maintenance and buffer stock in an imperfect production system", Computers and Industrial Engineering, 126, pp. 650-656 (2018).

2. Salmasnia, A., Abdzadeh, B., and Namdar, M. "A joint design of production run length, maintenance policy and control chart with multiple assignable causes", Journal of Manufacturing Systems, 42, pp. 44-56 (2017).

3. Rasay, H., Fallahnezhad, M.S., and Zaremehrjerdi, Y. "An integrated model of statistical process control and maintenance planning for a two stage dependent process under general deterioration", European Journal of Industrial Engineering, 13(2), pp. 149-177 (2019).

4. Rasay, H., Fallahnezhad, M.S., and Zaremehrjerdi, $Y$. "An integrated model for economic design of chisquare control chart and maintenance planning", Communications in Statistics-Theory and Methods, 47(12), pp. 2892-2907 (2017). DOI: $10.1080 / 03610926.2017 .1343848$

5. Chakraborty, T. and Giri, B.C. "Joint determination of optimal safety stocks and production policy for an imperfect production system", Applied Mathematical Modelling, 36, pp. 712-722 (2012).

6. Porteus, E.L. "Optimal lot sizing, process quality improvement and setup cost reduction", Operation Research, 34, pp. 137-144 (1986).

7. Rosenblatt, M.J. and Lee, H.L. "Economic production cycles with imperfect production processes", IIE Transactions, 18(1), pp. 48-55 (1986).

8. Groenevelt, H., Pintelon, L., and Seidmann, A. "Production lot sizing with machine break down", Management Science, 38, pp. 104-123 (1992).

9. Goyal, S.K. and Barron, C.L.E. "Economic production quantity with imperfect production system", Journal of Industrial Engineering, 34, pp. 33-36 (2005).

10. Chakraborty, T., Giri, B.C., and Chaudhuri, K.S. "Production lot sizing with process deterioration and machine breakdown", European Journal of Operational Research, 185, pp. 606-618 (2008).

11. Sana, S. "An economic production lot size model in an imperfect production system", European Journal of Operational Research, 201, pp. 158-170 (2010).

12. Sarkar, B. "An inventory model with reliability in an imperfect production process", Applied Mathematics and Computation, 218, pp. 4881-4891 (2012).
13. Horenbeek, A.V., Bure, J., Cattrysse, D., et al. "Joint maintenance and inventory optimization systems: A review", International Journal of Production Economics, 143, pp. 499-508 (2013).

14. Sarkar, B., Barron, L.E.C., Sarkar, M., et al. "An economic production quantity model with random defective rate, rework process and backorders for a single stage production system", Journal of Manufacturing Systems, 33(3), pp. 423-435 (2014). DOI: 10.1016/j.jmsy.2014.02.001

15. Sett, B.K., Sarkar, S., and Sarkar, B. "Optimal buffer inventory and inspection errors in an imperfect production system with preventive maintenance", International Journal of Advanced Manufacturing Technology, 90, pp. 545-560 (2016). DOI: 10.1007/s00170-0169359-9

16. Duffuaa, S., Kolus, A., Turki, U.A., et al. "An integrated model of production scheduling, maintenance and quality for a single machine", Computers and Industrial Engineering, 142 (2019). DOI: 10.1016/j.cie.2019.106239

17. Nourelfath, M., Nahas, N., and Ben-Daya, M. "Integrated preventive maintenance and production decisions for imperfect processes", Reliability Engineering \& System Safety, 148, pp. 21-31 (2016).

18. Fakher, H.B., Nourelfath, M., and Gendreau, M. "Integrating production, maintenance and quality: a multiperiod multi-product profit-maximization model", Reliability Engineering and System Safety, 170, pp. 191201 (2017). DOI: 10.1016/j.ress.2017.10.024

19. Cheng, G.Q., Zhou, B.H., and Li, L. "Integrated production, quality control and condition based maintenance for imperfect production systems", Reliability Engineering and System Safety, 175, pp. 251-264 (2018). DOI: $10.1016 /$ j.ress.2018.03.025

20. Shafiee-Gol, S., Nasiri, M.M., and Taleizadeh, A.A. "Pricing and production decision in multi-product single machine manufacturing system with discrete delivery and rework", OPSEARCH, 53, pp. 873-888 (2016). DOI: $10.1007 / \mathrm{s} 12597-016-0251-\mathrm{z}$

21. Hafidi, N., Barkany, A.E., Mhamedi, A.E., et al. "Integrated planning of production and maintenance for imperfect system with subcontracting strategies", International Journal of Engineering Business Management, 12, pp. 1-14 (2020).

22. Gomez, H.R., Gharbi, A., Kenne, J.P., et al. "Joint optimization of production and maintenance strategies considering a dynamic sampling strategy for a deteriorating system", Computers and Industrial Engineering, 140 (2020). DOI: 10.106/j.cie.2020.106273

23. Salmasnia, A., Hajihosseini, Z., Namdar, M., et al. "A joint determination of production cycle length, maintenance policy, and control chart parameters considering time value of money under stochastic shift size", Scientia Iranica, 27(1), pp. 427-447 (2020). 
24. Wang, L., Lu, Z., and Ren, Y. "Joint production control and maintenance policy for a serial system with quality deterioration and stochastic demand", Reliability Engineering and System Safety, 199 (2020). DOI: $10.1016 /$ j.ress.2020.106918

25. Jensen, M.T. "Generating robust and flexible job shop schedules using genetic algorithm", IEEE Transactions on Evolutionary Computation, 7, pp. 275-288 (2003).

26. Chou, C.Y. and Chen, C.H. "Economic design of variable sampling intervals T2 control charts using genetic algorithms", Expert Systems with Applications, 30, pp. 233-242 (2006).

\section{Biographies}

Seyed Mohammad Hadian is a $\mathrm{PhD}$ student of Industrial Engineering at university of Kurdistan, Sanandaj, Iran. He received his BSc and MSc degrees in Industrial Engineering from Babol university of technology and Shahid Bahonar University of Kerman, Kerman, Iran. His research interests are maintenance, quality control, production planning, and manufacturing systems.

Hiwa Farughi is an Associate Professor of Industrial Engineering at University of Kurdistan, Iran. He received his BSc and MSc degrees in Industrial Engineering from Amir Kabir University of Technology in 1998 and 2000 in Iran, respectively. He received his $\mathrm{PhD}$ degree in Industrial Engineering from Iran University of Science and Technology in 2012. His research interests included operation research, risk management, production planning, multi-objective programming, and scheduling and quality control.

Hasan Rasay received his $\mathrm{PhD}$ in Industrial Engineering from Yazd University, Yazd, Iran. Currently, he is an Assistant Professor of Industrial Engineering at Kermanshah University of Technology, Kermanshah, Iran. His research interests include reliability, quality control, quality engineering, and operations research. 